مجلة العلوم البيئية

معهد الدراسات والبحوث البيئية - جامعة عين شمس لبنه

عمر احمد علي علم الدين وآخرون

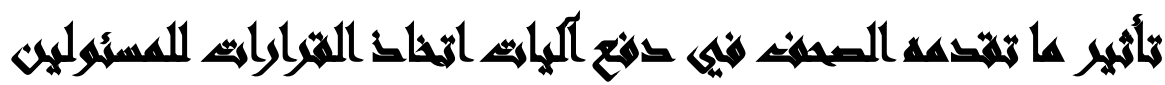

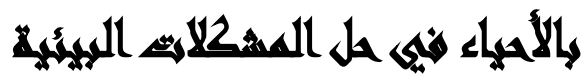

\section{شواسم تطليلية}

$$
\begin{aligned}
& \text { عمر أحمد علي علم الدين(')- عبد المسيح سمعان عبد المسيح(؟) } \\
& \text { مروى ياسين (ז) }
\end{aligned}
$$

( ) مجلة روزاليوسف r) معهد الدراسات والبحوث البيئية، جامعة عين شمس بالمس كلية الإعلام، جامعة بنى سويف روسف

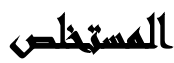

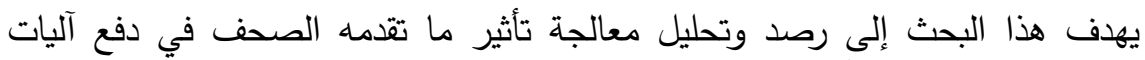

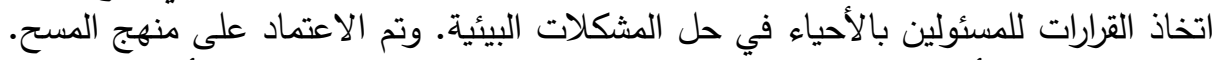

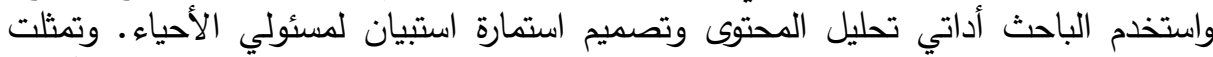

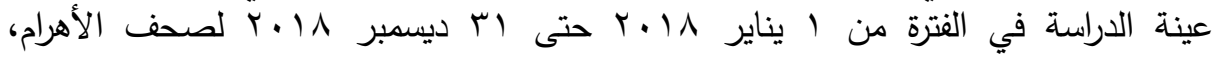
والمصري اليوم، والوفد.

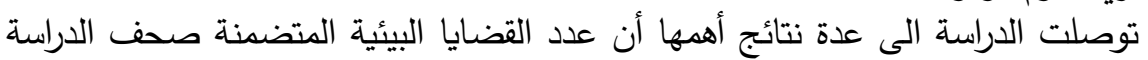

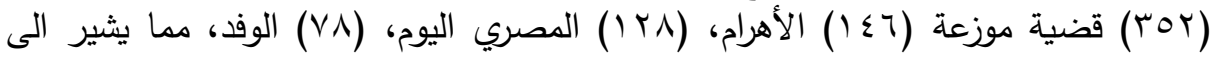

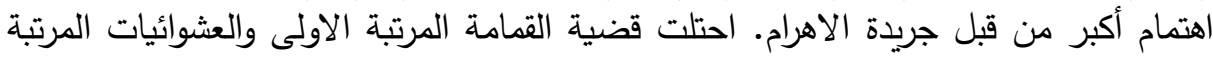

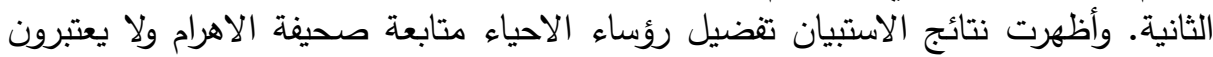

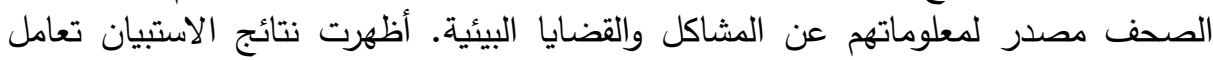

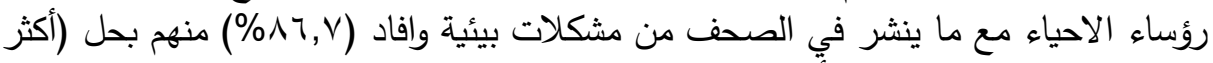

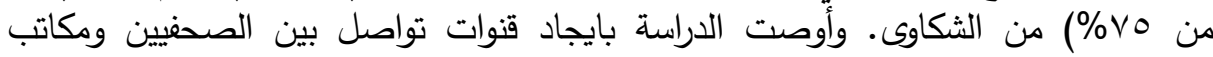

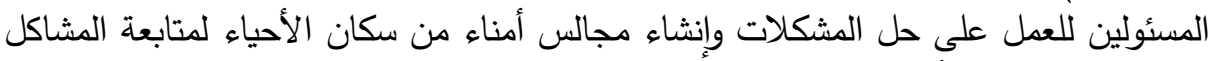
وحلها مع مسئولي الأحياء.

$$
\begin{aligned}
& \text { المجلد التاسع والأربعون، العدد السابع، الجزء السادس، يوليو •r. r. }
\end{aligned}
$$

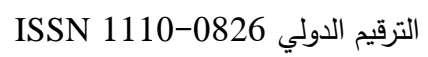


مجلة العلوم البيئية

معهد الدراسات والبحوث البيئية - جامعة عين شمس لبه

عمر احمد علي علم الدين وآخرون

\section{المهنبها}

تعد المشكلات البيئية وتناقص الموارد من الأمور التي تثغل العالم، خاصة بعد اكتثاف

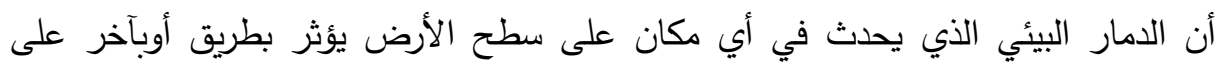

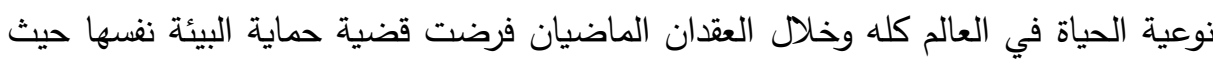
أدرك المجتمع أن المشاكل البيئية تعد أهم تحد لبقاء الإنسان واستمرار رفاهيته، وحقه كإنسان

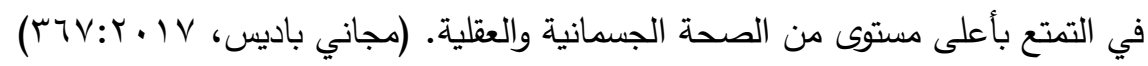

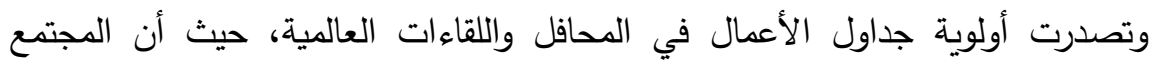

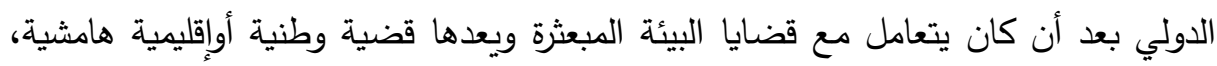

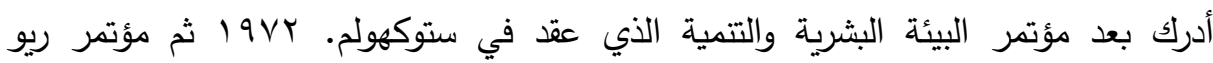

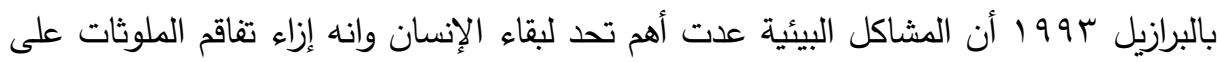

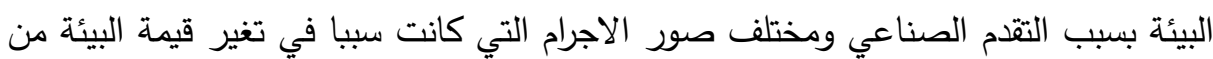

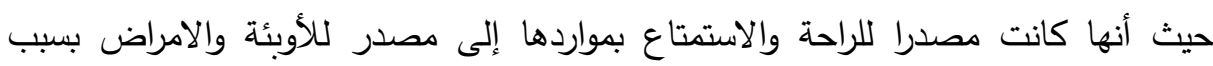

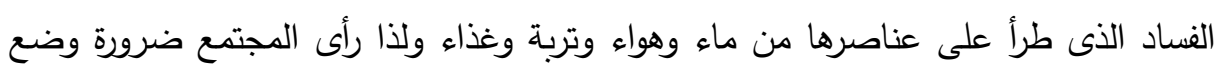

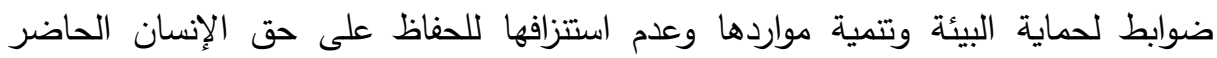

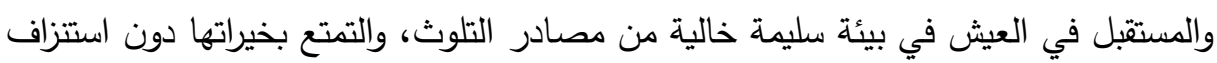

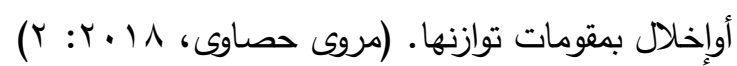

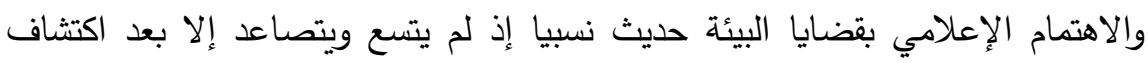
الآثار السلبية والمدمرة للبيئة الناتجة عن التطبيقات المعاصرة للتكنولوجيات الحديثة مما خلق لقائي اهتماما متزايدا بقضايا البيئة واستلزم قيام وسائل الإعلام بتسليط الضوه على المشكلات البيائية في محاولة للقضاء عليها أوالتخفيف من حدتها.

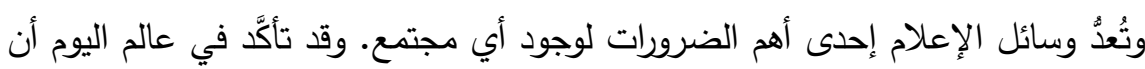
الاتصال الجماهيري ليس مجرَّ خاصية للتطور التكنولوجي الذي أنجزته الإنسانية، بل هو إند 216

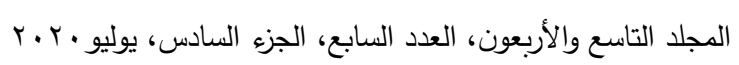

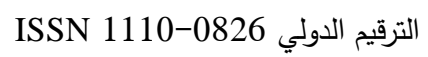




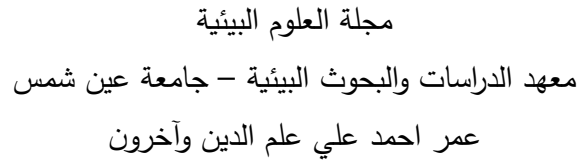

أحد أهم المقومات الأساسية التي لا يُمكن تصور الحياة دونها. إنها تؤدي وظيفةً مركَّبَة تتصل

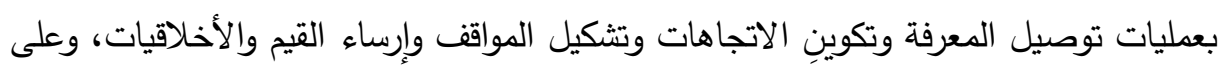

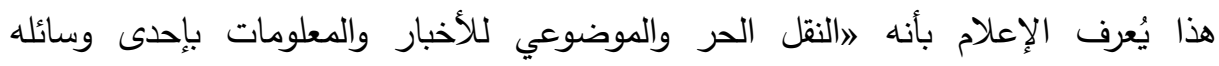
المختلفة، وأنه يستهدف العقل ويُككِن القول إن وسائل الإعلام المسموعة والمقروةة والمرئية قد

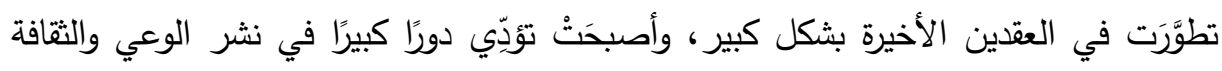
الجماهيرية، وأضحى للإعلام دور متميز في حماية البيئة.

(Media History Monographs 11:1, 2008 2009.E.M.Palmegiano,St).

وتقوم الصحافة بعدة أدوار في تعريف المواطنين بقضايا البيئة بصفة مستمرة وفى تعديل اتجاهاتهم وتغيير سلوكهم، عن طريق ما تقدمه من برامج عبر وسائل الاتصال الجماهيري

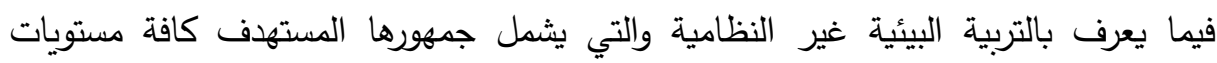
المجتمع على اختلاف اعمارهم ومستوياتهم الثقافية وتعتبر الصحافة كإحدى وسائل الاعلام

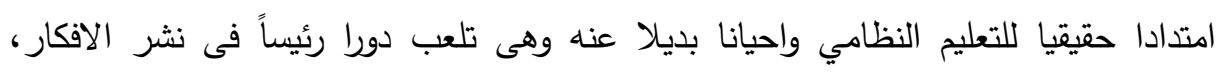
الصحافة تستطيع أن تقنع وبالتالي أن تغير كل من الاتجاه والسلوك، فهي اداة الاتصال

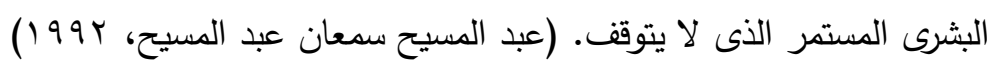

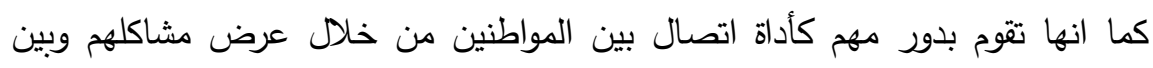

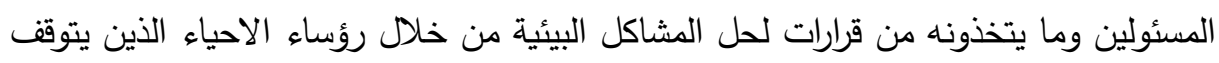

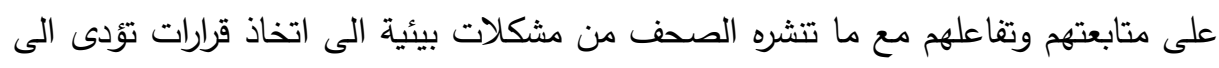

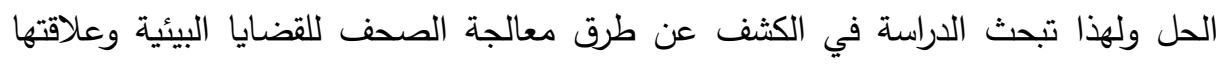

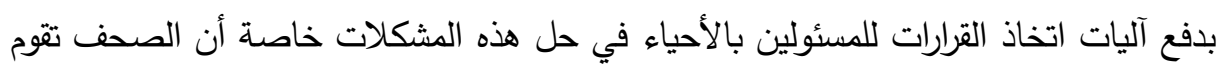

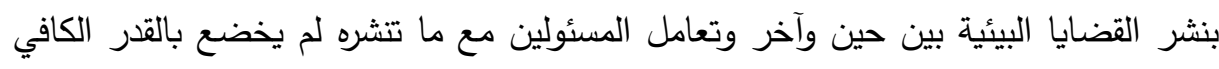




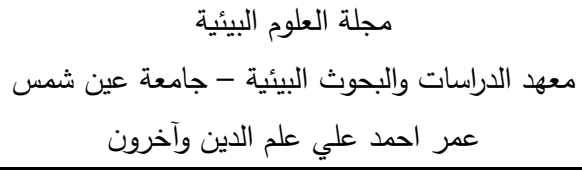

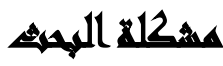

بمراجعة الدراسات السابقة ذات الصلة والاطلاع على البحوث والاحصائيات المتعلقة

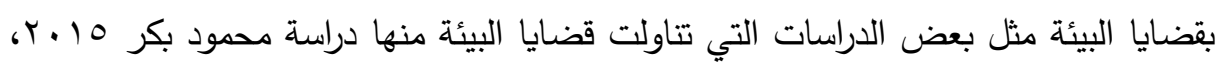

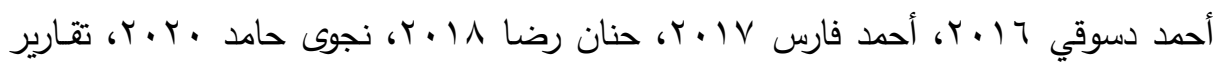
جهاز شئون البيئة.

تبين أن هناك ضرورة للاهتمام بدراسة العلاقة بين معالجة الصحف والمسئولين في آليات اتخاذ القرار تجاه القضايا البيئية، كما قام الباحثون بأجراء دراسة استطلاعية على عينة

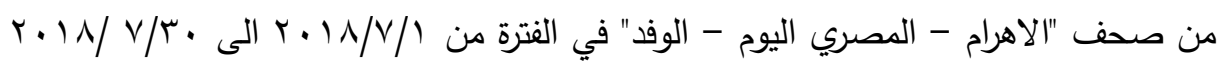
وبتحليل المحتوى لبعض القضايا البيئية تبين أن أهم المشكلات التي شملتها جريدة الأهرام هي

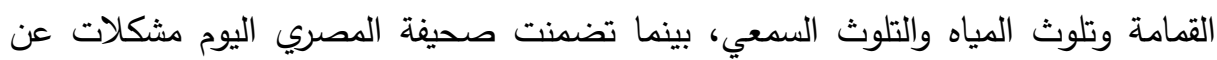
القمامة والصرف الصحي، فيما شملت المشكلات البيئة فى صحيفة الوفد الحديث عن القمامة والعشوائيات وخلال الدراسة الاستطلاعية ظهر مخاطبة الصحافة للمسئولين وكان هناك استجابة احيانا وحل للمشكلات البيئية.

اجرى الباحثون مقابلات شخصية مع 10 مسئولاً بالأحياء للتعرف على مدى استجابتهم

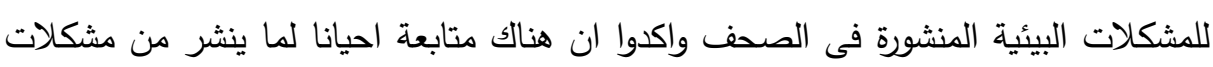

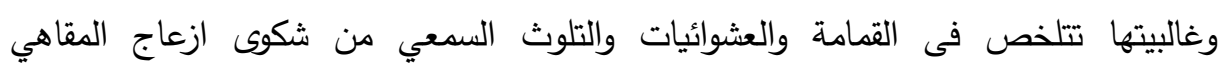

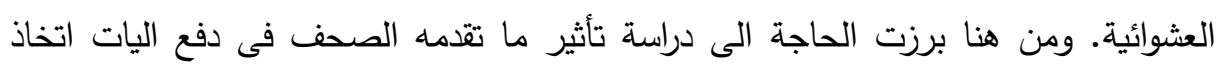

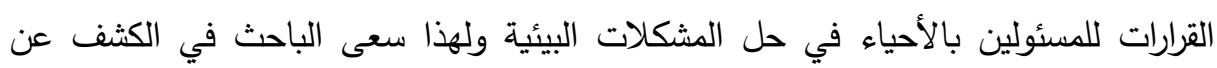
العلاقة بين ماتتشره الصحف وآليات اتخاذ القرار من المسئولين. 
مجلة العلوم البيئية

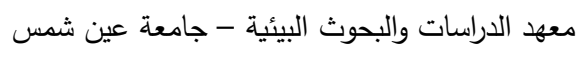

عمر احمد علي علم الدين وآخرون

\section{اسئلا المهيه}

يحاول البحث الاجابة عن هذه الاسئلة:

• ما المشكلات البيئية التي تصدرت أجندة صحف الدراسة خلال الفترة من يناير إلى

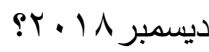

• ما مدى معالجة الصحف لهذه المشكلات؟

• ما مدى متابعة المسئول للصحف فى عرضها للمشكلات البيئية؟

• ما مدى استجابة المسئول لما تم نشره فى الصحف من حل للمشكلات البيئية؟

\section{أهسا اهم المهمث :}

تسعى الدراسة إلى تحقيق هدف رئيسي وهو: "الكثف عن تأثير الصحف في دفع آليات اتخاذ القرارات للمسئولين في حل المشكلات البيئية".

\section{أهمرية المهمث}

تعود أهمية الدراسة إلى:

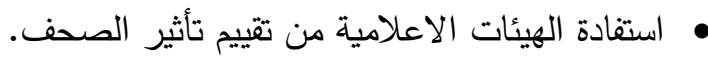

• استفادة المؤسسات الصحفية ومعرفة مدى متابعتها وتأثيرها فى حل المشكلات البيائية.

• ما تقدمه الدراسة من أدوات بحثية (استبيان، مقابلة شخصية، استمارة تحليل شكل مداتيل

$$
\text { ومضمون ) تمثل افادة لباحثون اخرون. }
$$

• استفادة رؤساء الاحياء بالدراسة من خلال تطبيق المقترحات وإعادة تقييم أهمية التواصل

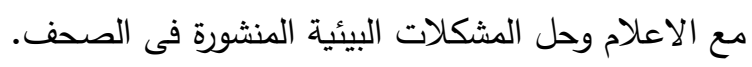

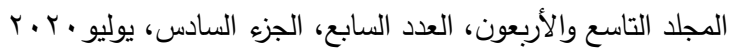

$$
\begin{aligned}
& \text { الترقيم الدولي 0826- ISSN 1110 }
\end{aligned}
$$


مجلة العلوم البيئية

معهد الدراسات والبحوث البيئية - جامعة عين شمس لبئة

عمر احمد علي علم الدين وآخرون

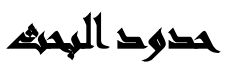

• اختار الباحثون الفترة من ا يناير حتى اب ديسمبر \1 إب وتمثل عينة الدراسة (الأهرام،

$$
\text { المصري اليوم، الوفد). }
$$

$$
\text { • مجموعة من رؤساء الاحياء. }
$$

مبررات الاختيار: هذه الصحف تمثل التيارات الصحفية المختلفة القومية والحزبية والمستقلة وتحظى قضايا البيئة فيها باهتمام، حيث تقرد لها الأهرام صفحات متخصصة، وتعتبرها الوفد

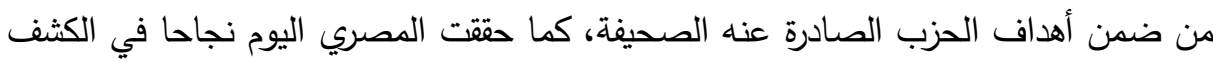

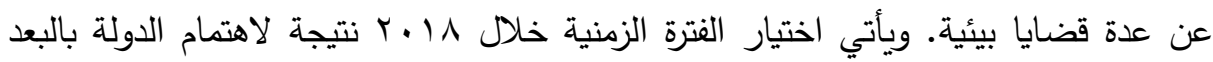

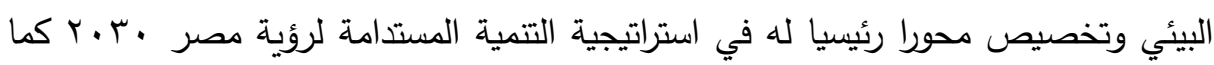

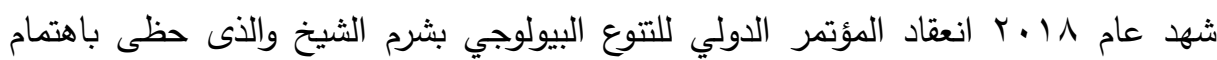
عالمى وإقليمي وافتتحه الرئيس عبد الفتاح السيسي.

\section{منهمج الهميه}

أعتمد البحث المنهج الوصفى وهو المنهج الاكثر مناسبة لا مكانيات الرصد الدقيق لمختلف جوانب البحث.

\section{أسوايت الهمثي}

• • استمارة تحليل محتوى "شكل - مضدون".

• استمارة استبيان للمقابلات الثخصية مع رؤساء الأحياء وصانعي القرار • • • •

$$
\begin{aligned}
& \text { المجلد التاسع والأربعون، العدد السابع، الجزء السادس، يوليو . F. } \\
& \text { الترقيم الدولي 0826-1110 }
\end{aligned}
$$


مجلة العلوم البيئية

معهد الدراسات والبحوث البيئية - جامعة عين شمس لبئة

عمر احمد علي علم الدين وآخرون

\section{مسطلحايت اللهمهي}

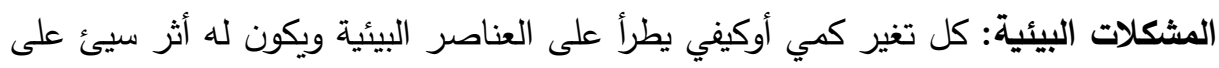

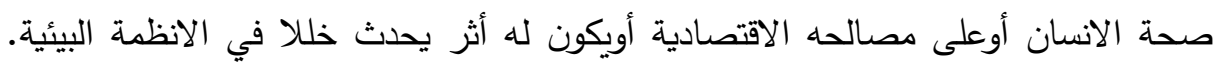

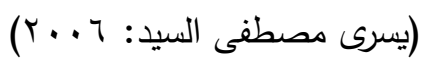

الصحافة: صناعة إصدار الصحف ونشر الرأي والتعليم والتسلية كما أنها واسطة تبادل الآراء

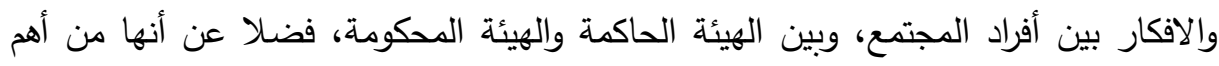

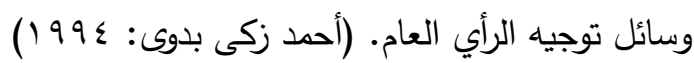
اتخاذ القرار: عملية معقدة يتم من خلالها اختيار الحل الملائم لمشكلة إدارية معينة مهما كانت

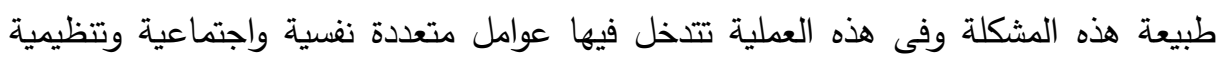

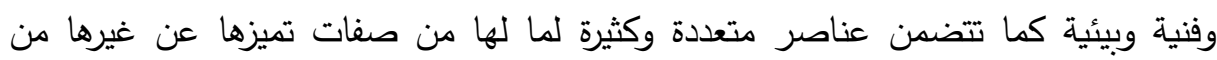
العمليات الادارية الاخرى. (نواف كنعان: 1991)

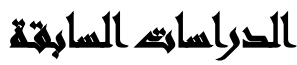

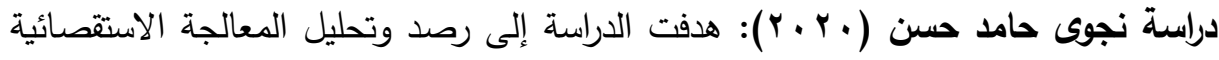

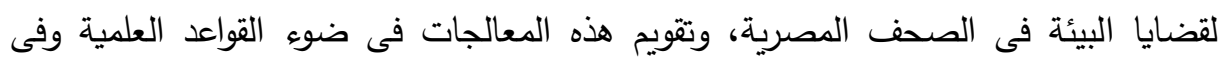

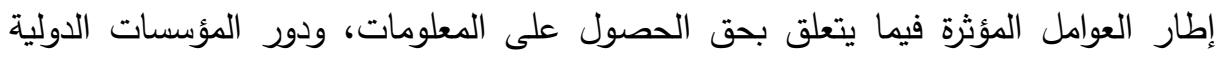

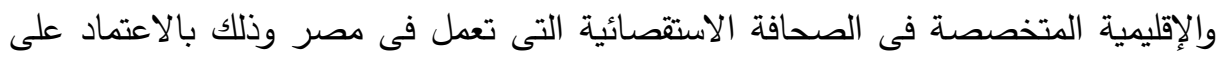

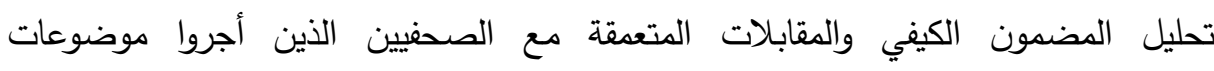

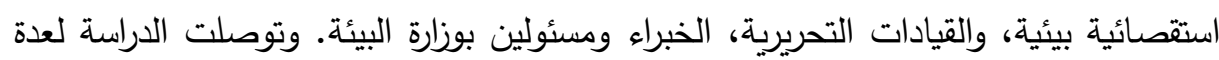

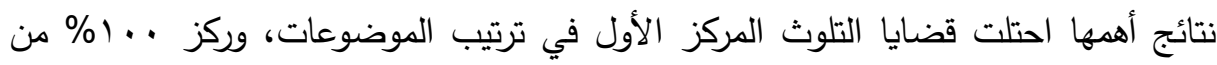
الموضوعات على توصيف المشكلة وشرح أسبابها والآثار المترتبة عليها.

$$
\begin{aligned}
& \text { المجلد التاسع والأربعون، العدد السابع، الجزء السادس، يوليو . F. }
\end{aligned}
$$

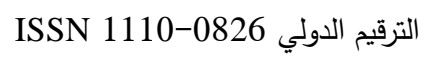


مجلة العلوم البيئية

معهد الدراسات والبحوث البيئية - جامعة عين شمس لبه

عمر احمد علي علم الدين وآخرون

دراسة نجلاء محروس (9 (19 ب): هدفت الدراسة إلى تقويم البرامج الخدمية لنشر المعلومات البيئية لدى مشاهدي القناة الثالثة (القاهرة) بالمناطق العشوائية للقاهرة الكبرى نطاق إرسال

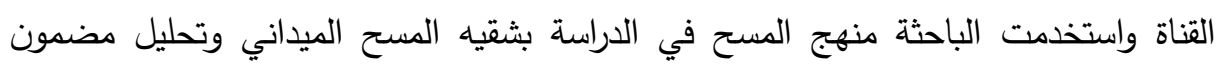

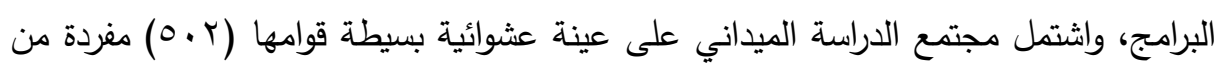

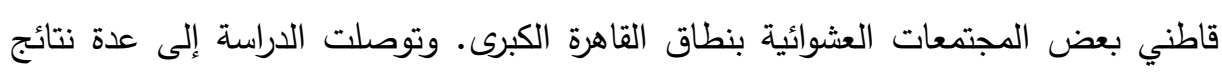
أهمها أن مشاهدي البرامج الخدمية أكثر معرفة بالمعلومات البيئية.

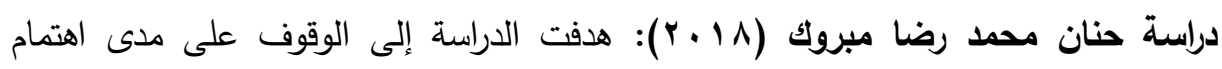

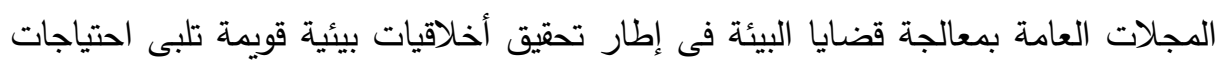

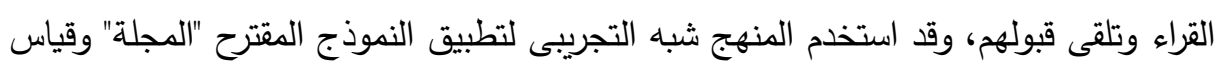
تأثيره فى تتمية أخلاقيات البيئة لدى مجموعة الدراسة (• ب فرد) من محافظتى القاهرة والجيزة. كما استخدم منهج المسح بثقيه الوصفى والتحليلى، وأعدت الدراسة قائمة بالأخلاقيات البيئية، فى مجلات الاهرام العربى، مجلة صباح الخير ومجلات التايم والنيوزويك الامريكية فى (الفترة

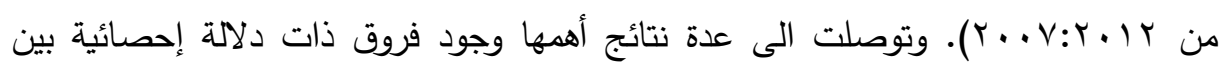

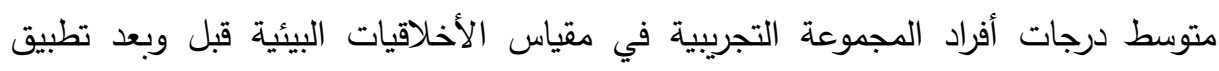
النموذج المقترح لصالح التطبيق البعدي وقد أوصت الدراسة بالتركيز على القضايا

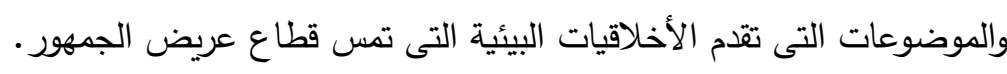

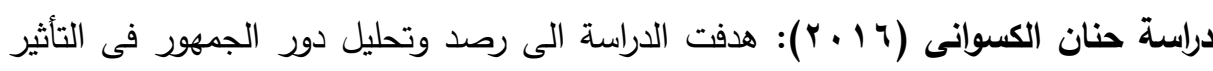

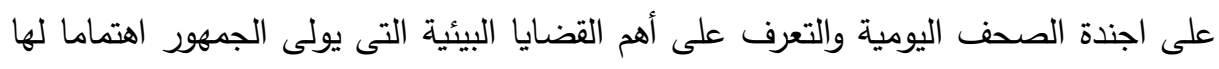

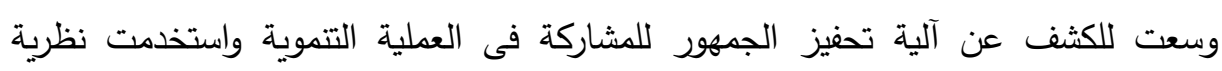

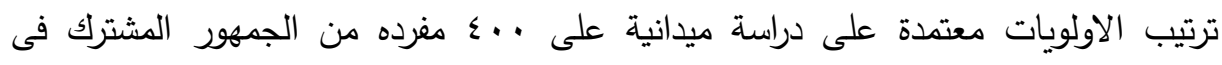

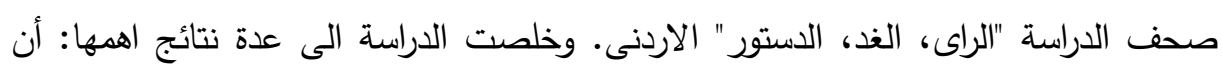

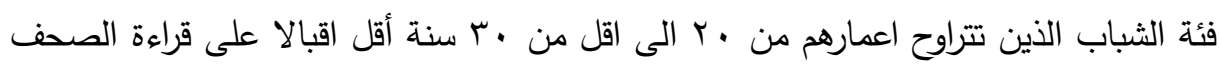

$$
\begin{aligned}
& \text { المجلد التاسع والأربعون، العدد السابع، الجزء السادس، يوليو •. F. }
\end{aligned}
$$

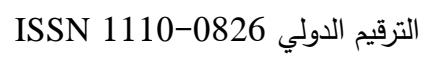




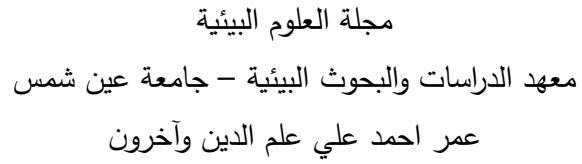

اليومية لمتابعتهم للصحف والمواقع الاككترونية، وأن قضية المتغير المناخى احتلت المرتبة الاولى تلتها ملوثات الهواء ثم النفيات الخطرة والاككترونية واعادة تدويرها.

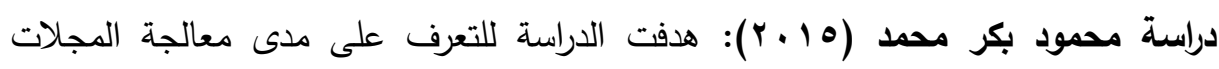

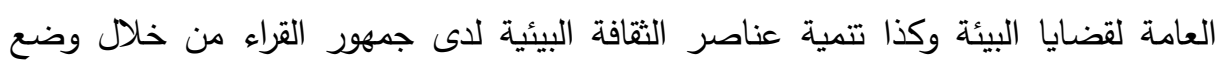
تصور علمى لتوظيف مضمون المجلات العامة لنشر الثقافة البيئية وقد تضمنت عينة تحليل المحتوى مجلات (أخر ساعة، المصور، أكتوبر). وتوصلت الدراسة الى عدة نتائج أهمها وجود قصور فى معالجة المجلات لقضايا البيئة ومشكلاتها وقلة الموضوعات البئ وتودلات البيئية مقارنة

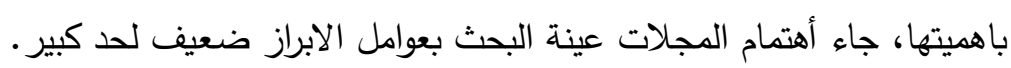

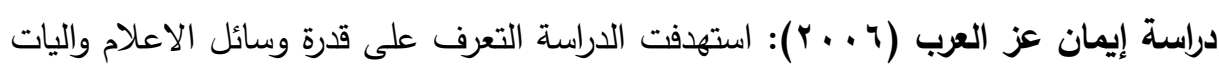

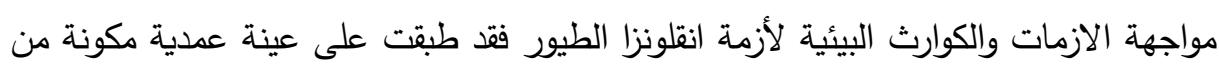
• 1 ا مفرده من النساء المربيات للطيور بمدينة ميت غمر بالدقهلية وتوصلت الدراسة الى انل التلفزيون جاء فى المرتبة الاولى التى تعتمد عليها العينة فى الحصول على بلى المعلومات يليه الراديوثم الصحف ثم الجيران والاصدقاء كما ابدت المبحوثات استعدادا لاتباع توجيهات وسائل الاعلام كعدم القاء الطيور النافقة فى الثوارع.

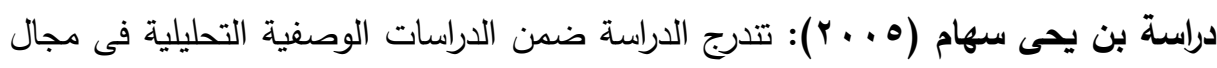
الاعلام، والتى تهدف الى رصد وتحليل خصائص المضمون الذى يقدم على صفحات الصحف حيث تدور اشكالية الدراسة حول أهمية الدور الذى تضطلع عليه الصحافة فى أهمية

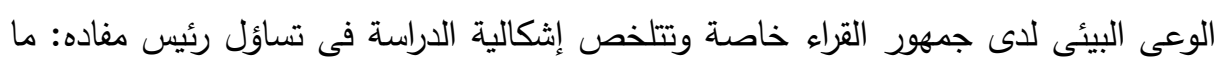

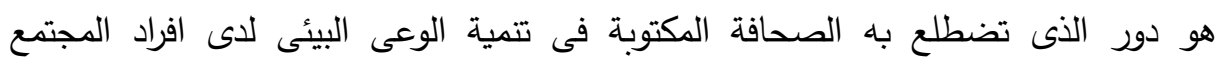

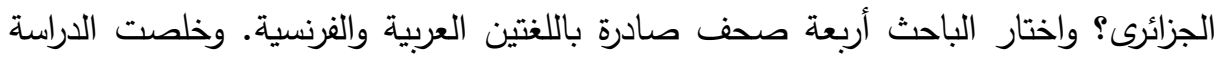

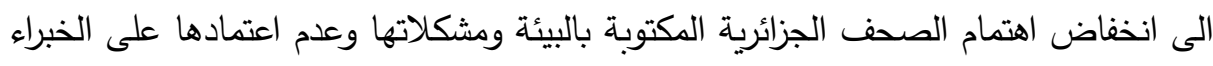

$$
\begin{aligned}
& \text { المجلد التاسع والأربعون، العدد السابع، الجزء السادس، يوليو • r. }
\end{aligned}
$$

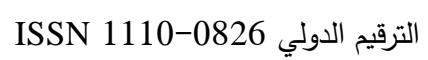


مجلة العلوم البيئية

معهد الدراسات والبحوث البيئية - جامعة عين شمس لبئة

عمر احمد علي علم الدين وآخرون

والمتخصصين فى مجال البيئة بالإضافة الى أهمالها لوسائل الابراز يقلل من فاعلية تغطياتها

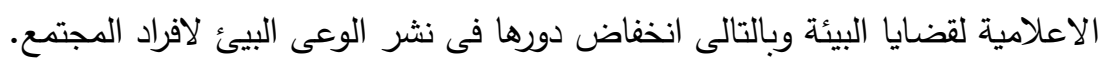

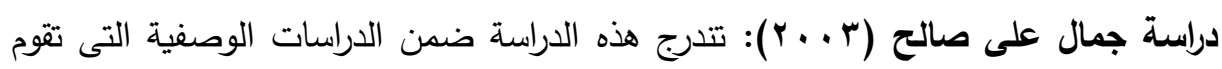
علي وصف الخصائص المختلفة، وجمع المعلومات حول موقف اجتماعى ،واستخدم الباحث فى الدراسة اسلوب المسح بهدف التعرف على الخصائص الاساسية التى يتميز بها جمهور

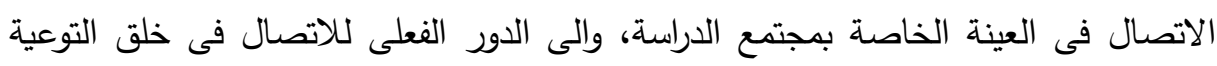

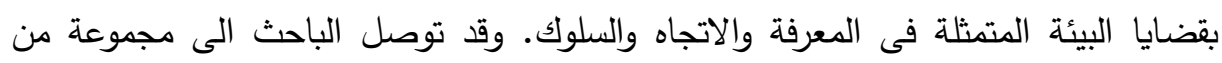

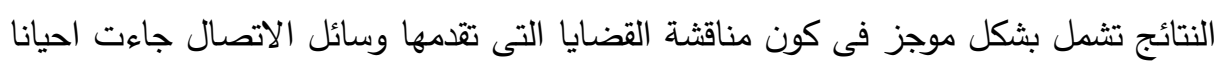

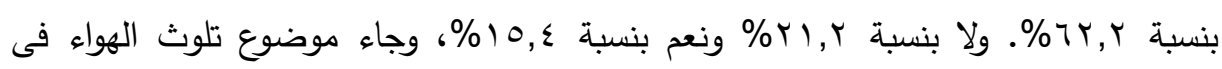

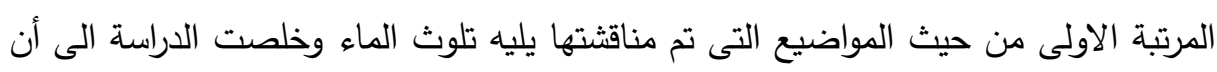

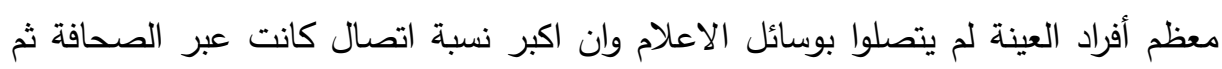
التلفزيون.

\section{الاطار المعرهي}

الصحافة هي عين الثعب علي الحاكمين والمسئولين وتساهم في زيادة الوعى من خلال المعرفة ، وفي هذا الميدان قال الرئيس الامريكي جيفرسون: (الصحافة هي خير اداة لتتوير

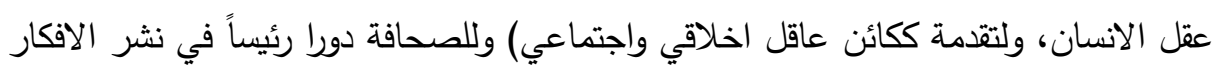

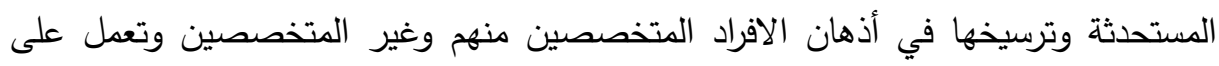

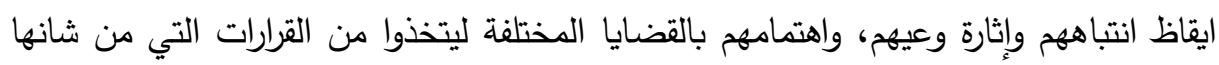

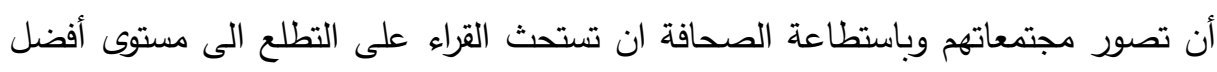

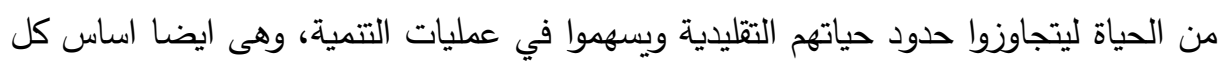

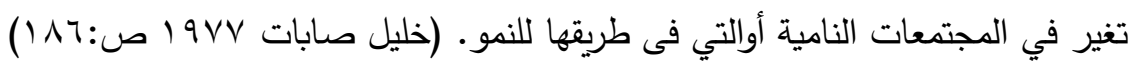

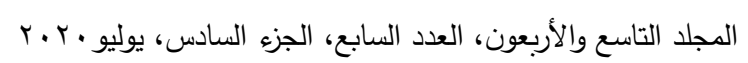

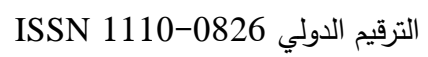




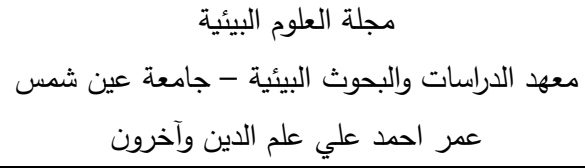

وتساهم الصحافة البيئية في معرفة كيفية التعامل مع البيئة وحل مشكلاتها وهى مهمة

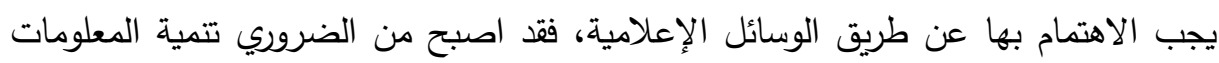

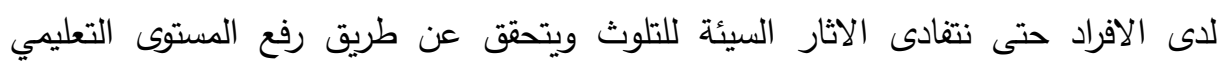

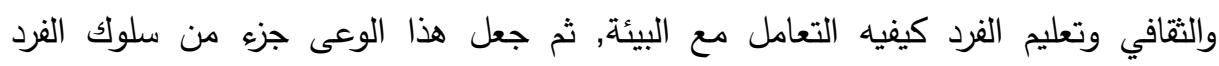

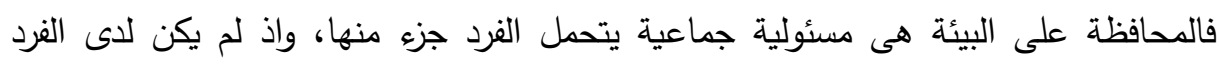

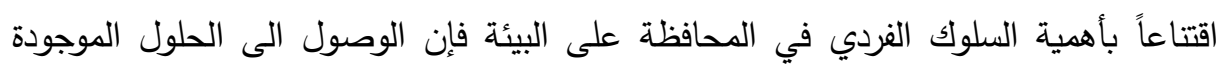

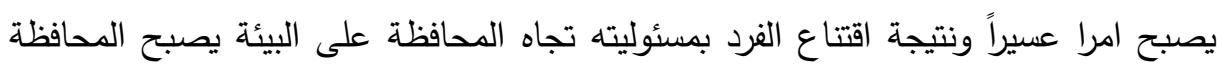

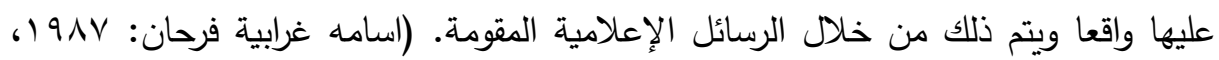

وتستطيع الصحافة البيئية أن تبسط أكثر القضايا البيئية تعقيد أذا ربطتها بحياة الناس هذا ما اكدته دراسة Betsy Byrum التى تتاولت كيفية معالجة عدد من الصحف الامريكية لقضية التغيرات المناخية وكيف ربطتها بحياة الناس من خلال رصد تاثيرات التغيرات المناخية على كافة مناحى الحياة وتوصلت الى ان اغلب المعالجات فى الصحف الامريكية أفتقد للعمق. (Betsy Bynum, 2016: p.85) وتتمثل أهمية الإدارة المحلية إنها تساهم في توافر تحديد أفضل لاحتياجات المواطنين

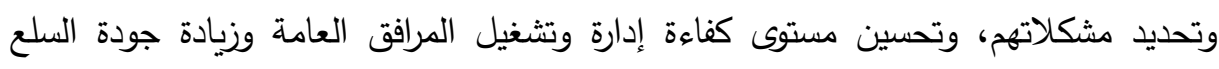
والخدمات للمواطنين وتخفيض النفقات العامة وتوظيف أفضل للموارد، وتتمية الكوادر الإدارية المحلية، وتقوية الرقابة وزيادة المساءلة والمحاسبة وتدفق المعلومات والحد من الفساد وزيادة

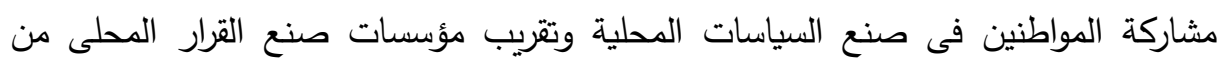
المواطنين وإتاحة فرصة أكبر للحوار والنقاش والتشاور والمشاركة، وزيادة الثقة بين المواطن والحكومة حيث أن السياسات المحلية تتعلق بالمصالح المباشرة للمواطنين. (محد عبد العال

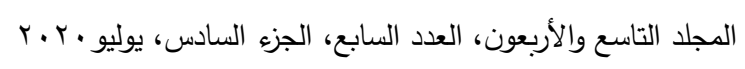

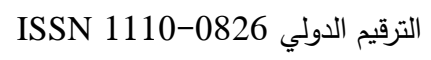


وتتقسم الادارة المحلية وفقا للمادة الاولى من نص مشروع قانون الإدارة المحلية الجديد ابريل V V • r، الى المحافظات، والمراكز ، والمدن، والأحياء، والوحدات المحلية القروية، ويكون

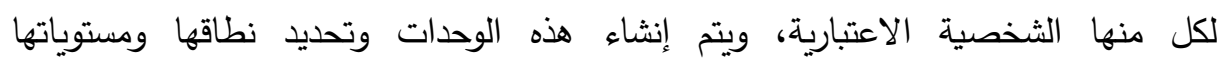
واختصاصاتها وتغيير أسمائها وإلغاؤها والية اتخاذ القرارات بها وفقاء للقانون.

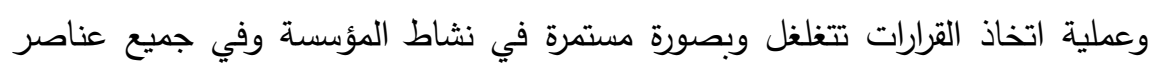

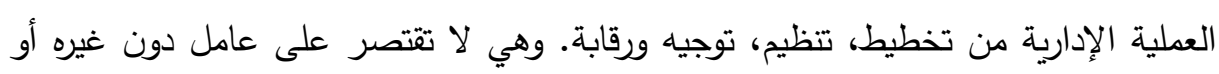
مستوى ادارى دون غيره فأي ادارى يتوجب عليه أن يمارسها لأداء مهامه وكى يتسنى لإنه له اتخاذ

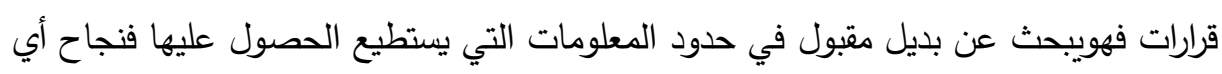

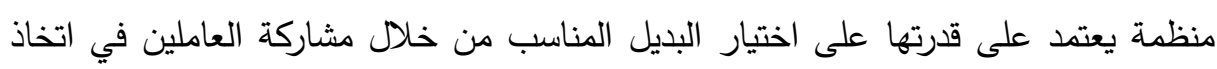

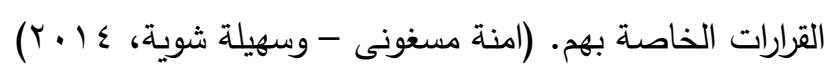
منهــج البحث: أعتمد البحث على منهج المسح وهو المنهج الاكثر مناسبة للبحوث

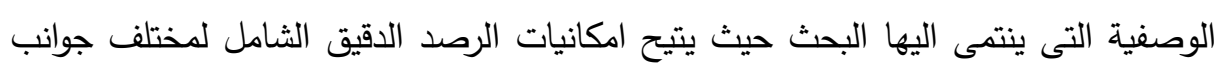

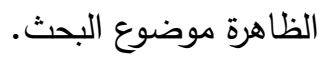
أدوات الاراســـة: قدم الباحث اكثر من أداة بحثية تمثلت في: استمارة تحليل المحتوى (شكل - مضمون)، لما تم كتابته من قضايا بيئية لصحف الاهرام والمصري اليوم والوفذ.

قام الباحثون بإعداد استمارة تحليل شكل ومضمون وتم عرضهما على السادة المحكمين وتم التعديل وفق ارائهم بالتركيز على البعد المعرفى كما تم إحصاء عدد التكرارات على عينة

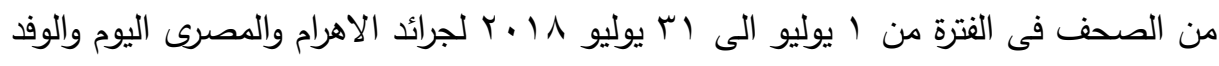

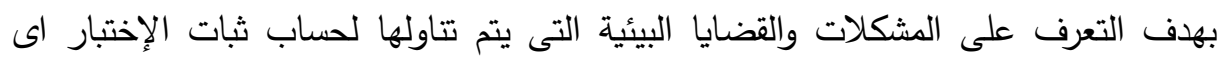

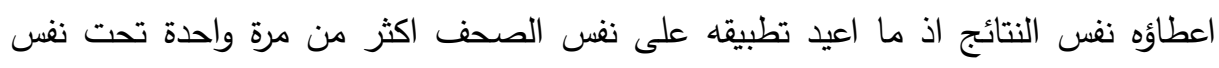

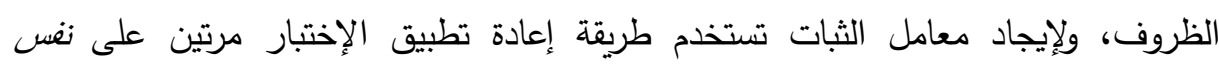
226

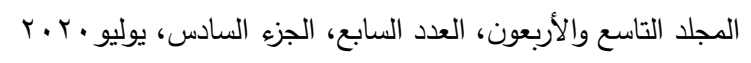

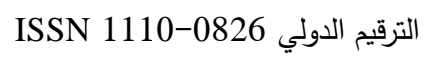




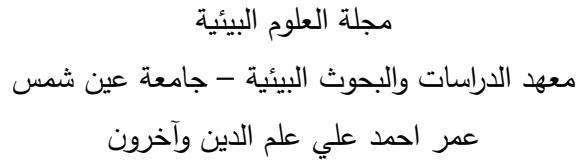

الصحف بعد فترة زمنية محددة رويتم حساب معامل الثبات لتحديد العلاقة بين مجموع الدرجات التى تم الحصول عليها فى الاختبارين بفاصل زمنى (10) يوم وقد قام الباحث بحساب ثباته بطريقة إعادة واتضح أن نسبة الاتفاق فى التطبيقين لتحليل المحتوى لفئة شكل الصورة كانت جميعها بنسبة اتفاق ( . (1\%). استمارة استبيان للتعرف على متابعة المسئولين بالأحياء للصحف وما تتشره من قضايا ومشكلات بيئية وهل هذا النشر يدعم الية اتخاذ القرار ويساهم فى حل المشكلات وقام الباحثون بالتحقق من ثبات استمارة الاستبيان باستخدام طريقة التجزئة النصفية، حيث تم تقسيم العبارات إلى قسمين: عبارات فردية، وعبارات زوجية، وحُسب معامل الارتباط بيرسون

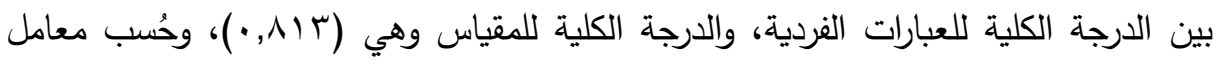

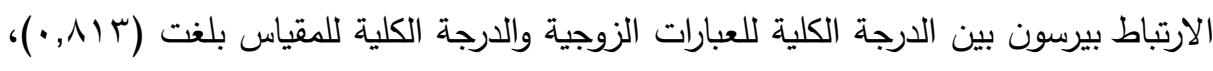

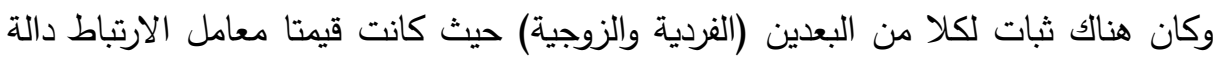

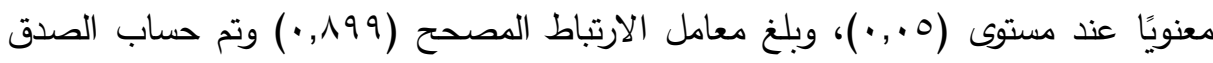

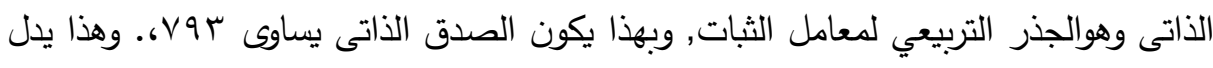
على الصدق.

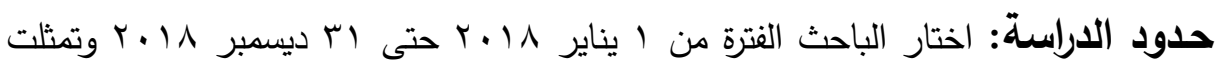
عينة الدراسة في صحف الأهرام، المصري اليوم، الوفد ويأتي اختيار الفترة الزمنية خلال

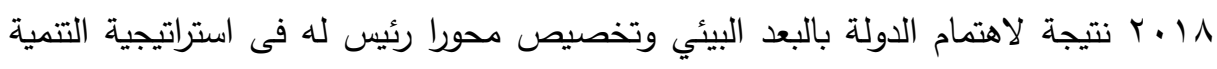

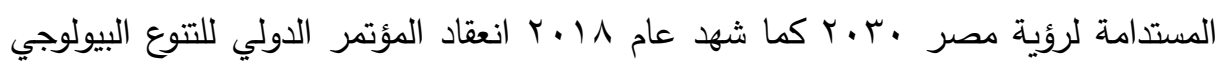
بشرم الثيخ والذى حظى باهتمام عالمي وإقليمي وافتتحه الرئيس عبد الفتاح السيسي. عينة الاراسة الميدانية: تم تطبيق عينة الدراسة على • ب رئيس حى من الصعيد (سوهاج واسيوط) والقاهرة الكبرى (القاهرة والجيزة والقليوبية) والاككندرية وذلك خلال الفترة من شهر

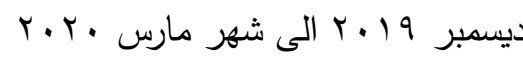

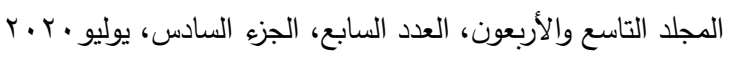

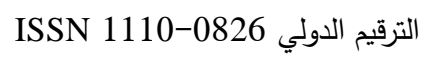


مجلة العلوم البيئية

معهد الدراسات والبحوث البيئية - جامعة عين شمس لبئه

عمر احمد علي علم الدين وآخرون

الاساليب الاحصائية المستخدمة: تم استخدام برنامج Spss للتحليل الإحصائي.

\section{اللمتائي}

أولاً: نتائج تحليل المضمون لعينة من الصحف المصرية المطبوعة (الأهرام - المصري اليوم

- الوفد) لتناول القضايا البيئية.

جدول (1):

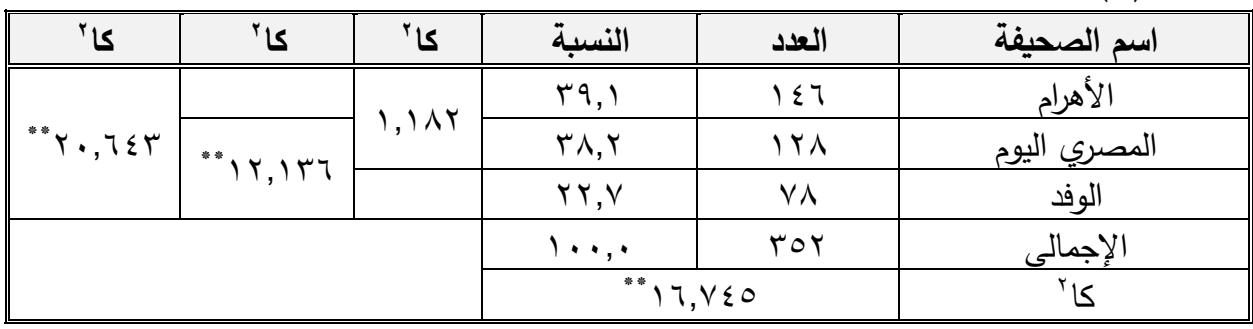

• عدد القضايا البيئية المتضمنة صحف الدراسة (الأهرام - المصري اليوم - الوفذ) بلغت

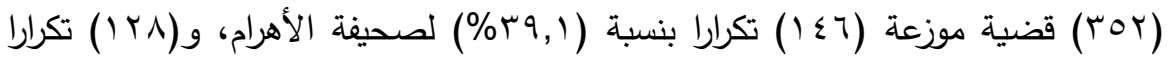

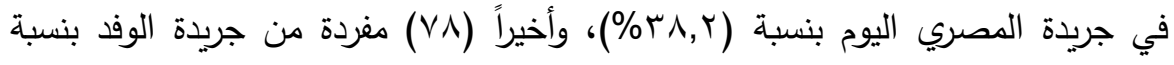

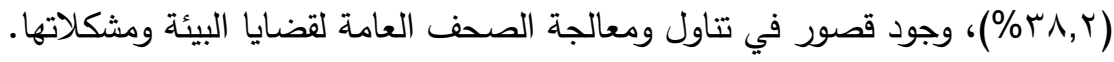

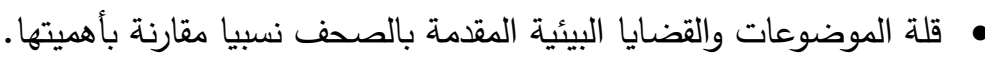


مجلة العلوم البيئية

معهد الدراسات والبحوث البيئية - جامعة عين شمس لبه

عمر احمد علي علم الدين وآخرون

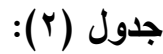

\begin{tabular}{|c|c|c|c|c|c|c|c|c|c|c|}
\hline \multirow{2}{*}{ المعنوبة الدالة } & \multirow{2}{*}{ كا' } & \multicolumn{2}{|c|}{ الإجمالي } & \multicolumn{2}{|c|}{ الوفذ } & \multicolumn{2}{|c|}{ المصري اليوم } & \multicolumn{2}{|c|}{ الأهرام } & \multirow{2}{*}{ القضية البيئية } \\
\hline & & $\%$ & ك & $\%$ & ك & $\%$ & ك & $\%$ & ك & \\
\hline$\cdot, 7$ & • & $1 r, 0$ & $\leq \varepsilon$ & $10, \varepsilon$ & Ir & r & IV & $1 \cdot, r$ & 10 & تلــوث \\
\hline$\cdot, r$ & r,orr & $i r, \Lambda$ & $\leq 0$ & $10, \varepsilon$ & Ir & $1 \cdot, r$ & ir & $i r, v$ & $r$. & تلـوث \\
\hline$\cdot, \ldots r$ & I r, rیY & $1 v, 9$ & r & $17, \mathrm{~V}$ & ir & $1 r, 0$ & 17 & $r r, r$ & $r \leq$ & عشوائيات \\
\hline$\cdot, 9$ & $\cdot, r \otimes \wedge$ & $\wedge, \wedge$ & ו & 11,0 & 9 & $\wedge, \uparrow$ & 11 & $v, 0$ & 11 & صرف صى صر \\
\hline$\cdot, \ldots 1$ & $|v, r| r$ & $r ч, \varepsilon$ & $1 \mathrm{rA}$ & $r \wedge, r$ & rr & $\leq 7,9$ & 7. & r & $\leq 7$ & القمامة \\
\hline., 0 & $1, r$ & $\varepsilon, r$ & 10 & 0,1 & $\varepsilon$ & $r, 1$ & $\varepsilon$ & $\varepsilon, \wedge$ & $\mathrm{V}$ & ضوضـاء \\
\hline$\cdot, \wedge$ & $\cdot, 0 \vee 1$ & $\varepsilon$, & $1 \leq$ & 0,1 & $\varepsilon$ & $r, 1$ & $\varepsilon$ & $\varepsilon, 1$ & 9 & غـلوث \\
\hline$\cdot, 0$ & $1, \varepsilon$ & $r, \Lambda$ & 1. & $r, T$ & $r$ & $r, r$ & $r$ & r, & 0 & زضاحات \\
\hline$\cdot, 7$ & rrr & $\cdot, 7$ & $r$ & $\cdot, \cdot$ & . & $\cdot, \cdot$ & - & $1, \varepsilon$ & $r$ & مدونة \\
\hline.,$\ldots 1$ & $17,7 \leq 0$ & $1 \ldots$, & ror & $r Y, V$ & $\vee \wedge$ & $r \Lambda, r$ & IrA & $r q, 1$ & $1 \leq 7$ & الإجمالي \\
\hline
\end{tabular}

احتلت قضية القمامة ومشاكلها المرتبة الاولى بين القضايا التى تتاولتها الدراسة بالتحليل

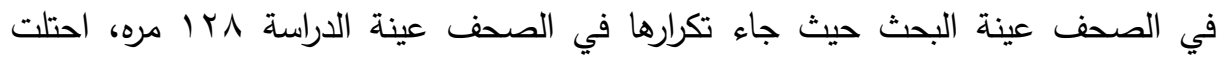
المصرى اليوم المرتبة الاولى في التكرار ب • 7 مره بينما جاءت الاهرام بـ؛ مره وكان التكرار في الوفد r... كما احتلت العشوائيات المرتبة الثانية في تكرار القضايا والمشكلات البيئية بrا مره في التكرار الخاص بصحف الدراسة بينما احتلت تلوث الهواء المرتبة الثالثة بتكرار 
مجلة العلوم البيئية

معهد الدراسات والبحوث البيئية - جامعة عين شمس لإسل

عمر احمد علي علم الدين وآخرون

هـ مره وجاء في المرتبة الرابعة تلوث المياه بـ

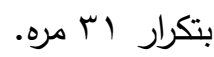

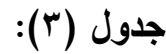

\begin{tabular}{|c|c|c|c|c|c|c|c|c|c|c|c|}
\hline \multirow{2}{*}{ 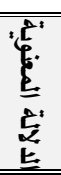 } & \multirow{2}{*}{$\vec{a}$} & \multicolumn{2}{|c|}{ الإجمالي } & \multicolumn{2}{|c|}{ الوفــ ل الوفـ } & \multicolumn{2}{|c|}{ المصري اليوم } & \multicolumn{2}{|c|}{ الأهرام } & \multirow{2}{*}{ الصحفية } & \multirow{2}{*}{ 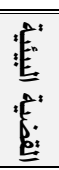 } \\
\hline & & $\%$ & s & $\%$ & ك & $\%$ & s & $\%$ & s & & \\
\hline \multirow{8}{*}{$\vdots$} & \multirow{8}{*}{$\Xi$} & $r v, r$ & ir & $\varepsilon 1, v$ & 。 & $1 v, 4$ & $r$ & $r q, v$ & $\varepsilon$ & خبر & \multirow{8}{*}{ 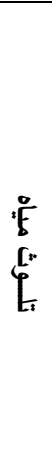 } \\
\hline & & ro & 11 & $\Lambda, r$ & 1 & $r q, \varepsilon$ & 。 & $r r, r$ & 。 & تقرير & \\
\hline & & . & . & . & . & . & . & . & . & مقال & \\
\hline & & ro & 11 & o. & 1 & 11,1 & $r$ & $i r, r$ & r & تحقيق & \\
\hline & & $1 \Lambda, r$ & $\wedge$ & . & . & $r o, r$ & 9 & $1 \mu, r$ & $r$ & بريد قراء & \\
\hline & & $\varepsilon, 0$ & $r$ & . & . & 0,9 & 1 & $\uparrow, V$ & 1 & حوار صحفي & \\
\hline & & $r, r$ & 1 & . & . & . & . & $\checkmark, V$ & 1 & صورة وتعليق & \\
\hline & & $1 \ldots$ & 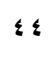 & $r v, r$ & ir & $r \Lambda, \uparrow$ & iv & $r \leqslant, 1$ & 10 & الإجمالي & \\
\hline \multirow{8}{*}{$\because$} & \multirow{8}{*}{$\begin{array}{l}0 \\
0 \\
z \\
z\end{array}$} & $r \cdot, \cdot$ & 9 & $14, \mathrm{~V}$ & $r$ & $r+1$ & $r$ & r. & $\varepsilon$ & خبر & \multirow{8}{*}{ 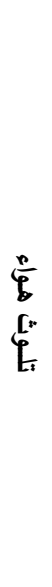 } \\
\hline & & $r \mu, r$ & 10 & $r \mu, r$ & $\varepsilon$ & $\leq 4, r$ & 1 & ro & - & تقرير & \\
\hline & & 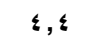 & $r$ & $\Lambda, r$ & 1 &.,. & . & 。 & 1 & مقال & \\
\hline & & rr, r & 1. & $r_{0, .}$ & $r$ & $\cdot, \cdot$ & . & ro & $v$ & تحقيق & \\
\hline & & $i r, r$ & 7 & $14, v$ & r & $10, \xi$ & r & 1. & r & بريد قراء & \\
\hline & & $\checkmark, V$ & $r$ & $\cdot, \cdot$ & . & $10, \xi$ & r & 。 & 1 & حوار صحفي & \\
\hline & & . & . & . & . & . & . & . & . & صورة وتعليق & \\
\hline & & $1 \ldots$, & $\leqslant 0$ & $r \Psi, V$ & ir & $r \wedge, q$ & ir & £ $\{$, & r. & الإجمالي & \\
\hline
\end{tabular}

230

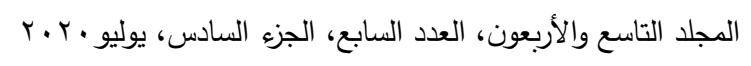

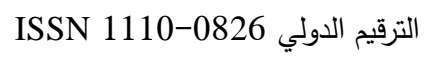


مجلة العلوم البيئية

معهد الدراسات والبحوث البيئية - جامعة عين شمس لبه عمر احمد علي علم الدين وآخرون

\begin{tabular}{|c|c|c|c|c|c|c|c|c|c|c|c|}
\hline \multirow{2}{*}{ 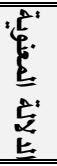 } & \multirow{2}{*}{$\bar{n}^{2}$} & \multicolumn{2}{|c|}{ الإجمالي } & \multicolumn{2}{|c|}{ الوف } & \multicolumn{2}{|c|}{ المصري اليوم } & \multicolumn{2}{|c|}{ الأهرام } & \multirow{2}{*}{ الصحفية الأثكال } & \multirow{2}{*}{ 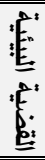 } \\
\hline & & $\%$ & كs & $\%$ & ك & $\%$ & كs & $\%$ & كs & & \\
\hline \multirow{8}{*}{$\vdots$} & \multirow{8}{*}{$\begin{array}{l}\overrightarrow{0} \\
\therefore \\
0\end{array}$} & $r \wedge, \uparrow$ & 11 & $r r, 1$ & $r$ & $\varepsilon r, \Lambda$ & $v$ & $r r, 0$ & $\wedge$ & خبر & \\
\hline & & $\cdot, \cdot$ & . & $\cdot, \cdot$ & . & $\cdot, \cdot$ & . & $\cdot, \cdot$ & . & تقريز & \\
\hline & & $r Y, r$ & $1 \varepsilon$ & $\leq Y, r$ & 1 & $7, r$ & 1 & $r \cdot, r$ & $\mathrm{v}$ & مقال & \\
\hline & & $19,$. & ir & $10, \varepsilon$ & $r$ & $r, r$ & 0 & $1 \leqslant, V$ & 0 & تحقيق & \\
\hline & & $r, r$ & r & $v, v$ & 1 & $\cdot, \cdot$ & . & $r, q$ & 1 & بريد قراء & \\
\hline & & 1,7 & 1 & $\cdot, \cdot$ & . & $\cdot, \cdot$ & . & $r, q$ & 1 & حوار صحفي & \\
\hline & & $r \wedge, \uparrow$ & 11 & $r r, 1$ & $r$ & $\varepsilon r, \Lambda$ & $v$ & $r r, \theta$ & $\wedge$ & صورة وتعليق & \\
\hline & & $1 \ldots$, & rי & $r \cdot, r$ & ir & $r_{0, \varepsilon}$ & 17 & $0 \leqslant, \cdot$ & $r \varepsilon$ & الإجمالي & \\
\hline \multirow{8}{*}{$\therefore$} & \multirow{8}{*}{$\because$} & $r Y, Y$ & $v$ & & 1 & 9,1 & 1 & $\{0,0$ & 0 & خبر & \multirow{8}{*}{$\begin{array}{l}q \\
b \\
b\end{array}$} \\
\hline & & $1 Y, q$ & $\varepsilon$ & 11,1 & 1 & 9,1 & 1 & $1 \wedge, r$ & $r$ & تقرير & \\
\hline & & $\therefore$ & . & $\cdot$, & . & $\cdot, \cdot$ & . & $\cdot, \cdot$ & . & مقال & \\
\hline & & $r Y, T$ & $\mathrm{v}$ & $\varepsilon \varepsilon, \varepsilon$ & $\varepsilon$ & 9,1 & 1 & $1 \Lambda, r$ & $r$ & تحقيق & \\
\hline & & $r \wedge, \nu$ & ir & $r \mu, r$ & $r$ & $V r, V$ & $\Lambda$ & 9,1 & 1 & بريد قراء & \\
\hline & &., & . & $\cdot, \cdot$ & . & $\cdot, \cdot$ & . & $\cdot, \cdot$ & . & حوار صحفي & \\
\hline & & $r, r$ & 1 & $\cdot, \cdot$ & . & $\cdot, \cdot$ & . & 9,1 & 1 & صورة وتعليق & \\
\hline & & $1 \ldots$, & $\mu_{1}$ & rq,. & 9 & $r_{0,0}$ & 11 & $r_{0,0}$ & 11 & الإجمالي & \\
\hline \multirow{8}{*}{$\vdots$} & \multirow{8}{*}{$\begin{array}{l}5 \\
\vdots \\
\vdots \\
0\end{array}$} & $r v, r$ & ro & $r v, r$ & 1 & $1 \wedge, r$ & 11 & $r q, 1$ & 11 & خبر & \multirow{8}{*}{$\underline{E_{1}^{\prime}}$} \\
\hline & & $r, r$ & $\varepsilon$. & $r v, r$ & 1 & $r ४, V$ & 17 & $r q, 1$ & 11 & تقرير & \\
\hline & & $\mathrm{v}, \wedge$ & 1. & YY,V & . & $r, r$ & $r$ & 9,0 & $r$ & مقال & \\
\hline & & $v, \wedge$ & 1. & $1 r, 4$ & $r$ & $0,$. & $r$ & $\Lambda, \vee$ & $\varepsilon$ & تحقيق & \\
\hline & & ro,. & rY & 9,1 & $r$ & $\leq 0,$. & $r v$ & 7,0 & $r$ & بريد قراء & \\
\hline & & $\cdot, \cdot$ & . & $\cdot, \cdot$ & . & $\cdot, \cdot$ & . & $\cdot, \cdot$ & . & حوار صحفي & \\
\hline & & $\cdot, \wedge$ & 1 & $\cdot$, & . & $1, v$ & 1 & $\cdot, \cdot$ & . & صورة وتعليق & \\
\hline & & $1 \ldots$, & IrA & $i v, r$ & rr & $\leq 4,9$ & 7. & $r 0, q$ & $\leq 4$ & الإجمالي & \\
\hline
\end{tabular}

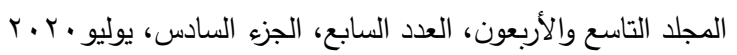

الترقيم الدولي 0826-0 الانون، 
مجلة العلوم البيئية

معهد الدراسات والبحوث البيئية - جامعة عين شمس لبئه

عمر احمد علي علم الدين وآخرون

\begin{tabular}{|c|c|c|c|c|c|c|c|c|c|c|c|}
\hline \multirow{2}{*}{ 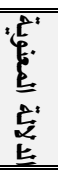 } & \multirow[b]{2}{*}{$\vec{n}$} & \multicolumn{2}{|c|}{ الإجمالي } & \multicolumn{2}{|c|}{ الوفد } & \multicolumn{2}{|c|}{ المصري اليوم } & \multicolumn{2}{|c|}{ الأهرام } & \multirow{2}{*}{ الصحفية } & \multirow{2}{*}{ 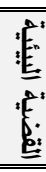 } \\
\hline & & $\%$ & s & $\%$ & ك & $\%$ & ك & $\%$ & ك5 & & \\
\hline \multirow{8}{*}{$\therefore$} & \multirow{8}{*}{$\vdots$} & $Y, V$ & 1 & $\cdot, \cdot$ & . & $\cdot, \cdot$ & . & $1 \leq, r$ & 1 & خبر & \multirow{8}{*}{$\stackrel{\square}{\xi}$} \\
\hline & & $r \cdot, \cdot$ & $r$ & $\cdot, \cdot$ & . & ro,. & 1 & & r & تقرير & \\
\hline & & 7,8 & 1 & $\cdot, \cdot$ & . & $\cdot, \cdot$ & . & $1 \leq, r$ & 1 & مقال & \\
\hline & & $r q, V$ & $\varepsilon$ & $v_{0, .}$ & $r$ & $\cdot, \cdot$ & . & $1 \leqslant, r$ & 1 & تحقيق & \\
\hline & & $\varepsilon \cdot, \cdot$ & 7 & ro,. & 1 & $v_{0},$. & $r$ & $r \wedge, r$ & r & بريد قراء & \\
\hline & & $\cdot, \cdot$ & . & $\cdot, \cdot$ & . &.,$\cdot$ & . & $\cdot, \cdot$ & . & حوار صحفي & \\
\hline & & $\cdot$, & . & $\cdot, \cdot$ & . & $\cdot, \cdot$ & . & $\cdot, \cdot$ & . & صورة وتعليق & \\
\hline & & $1 \cdots$, & 10 & $r ४, \vee$ & $\varepsilon$ & $Y \Psi, V$ & $\varepsilon$ & $\leq \neg, \vee$ & $v$ & الإجمالي & \\
\hline \multirow{8}{*}{ 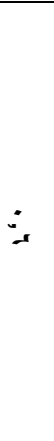 } & \multirow{8}{*}{$\vdots$} & $\leq Y, q$ & 1 & ro,. & 1 & $v_{0},$. & $r$ & r r & r & خبر & \multirow{8}{*}{$\begin{array}{l}\frac{r}{b} . \\
\frac{[n}{b}\end{array}$} \\
\hline & & $r 1, \varepsilon$ & $r$ & ro,. & 1 & ro,. & 1 & $17, v$ & 1 & تقرير & \\
\hline & & . & . & . & . & . & . & . & . & مقال & \\
\hline & & $r \Delta, v$ & 0 & $0 .,$. & $r$ & . & . & $0 .,$. & $r$ & تحقيق & \\
\hline & & $\cdot$ & . & . & . & . & . & . & . & بريد قراء & \\
\hline & & . & . & . & . & . & . & . & . & حوار صحفي & \\
\hline & & - & . & - & . & . & . & - & . & صورة وتعليق & \\
\hline & & $1 \ldots$, & $1 \leq$ & $r \wedge, \uparrow$ & $\varepsilon$ & $r \Lambda, Y$ & $\varepsilon$ & $\leq r, q$ & 7 & الإجمالي & \\
\hline \multirow{8}{*}{$\vdots$} & \multirow{8}{*}{$\vdots$} & $v \cdot, \cdot$ & $v$ & $0 .,$. & 1 & $1 \ldots$, & $r$ & $7,$. & $r$ & خبر & \multirow{8}{*}{ 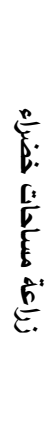 } \\
\hline & & $1,, 0$ & 1 & . & . & . & . & $r \cdot, \cdot$ & 1 & تقرير & \\
\hline & & $1,, 0$ & 1 & · & . & . & · & $r \cdot, \cdot$ & 1 & مقال & \\
\hline & & $1 \cdot, \cdot$ & 1 & $0 .,$. & 1 & . & . & . & . & تحقيق & \\
\hline & & . & . & . & . & . & . & . & . & بريد قراء & \\
\hline & & . & . & . & . & . & . & . & • & حوار صحفي & \\
\hline & & . & . & . & . & . & . & . & . & صورة وتعليق & \\
\hline & & $1 \ldots$, & 1. & $r_{\cdot}, \cdot$ & $r$ & $r \cdot, \cdot$ & $r$ & $0 ., \cdot$ & 0 & الإجمالي & \\
\hline
\end{tabular}


مجلة العلوم البيئية

معهد الدراسات والبحوث البيئية - جامعة عين شمس لبئه

عمر احمد علي علم الدين وآخرون

\begin{tabular}{|c|c|c|c|c|c|c|c|c|c|c|c|}
\hline \multirow{2}{*}{$\frac{E^{2}}{E^{2}}$} & \multirow{2}{*}{$\vec{n}$} & \multicolumn{2}{|c|}{ الإجمالي } & \multicolumn{2}{|c|}{ الوفد } & \multicolumn{2}{|c|}{ المصري اليوم } & \multicolumn{2}{|c|}{ الأهرام } & \multirow{2}{*}{ الصحفية } & \multirow{2}{*}{ 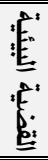 } \\
\hline & & $\%$ & ك & $\%$ & ك & $\%$ & 5 & $\%$ & ك & & \\
\hline \multirow{8}{*}{$\because$} & \multirow{8}{*}{ 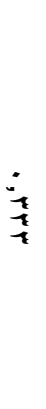 } & . & . & . & . & . & . & . & . & خبر & \multirow{8}{*}{ 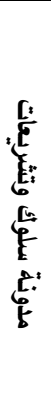 } \\
\hline & & $0 ., \cdot$ & 1 & . & . & . & . & $0,, \cdot$ & 1 & تقريز & \\
\hline & & . & . & . & - & . & . & . & . & مقال & \\
\hline & & $0,, \cdot$ & 1 & - & . & . & . & $0,, \cdot$ & 1 & تحقيق & \\
\hline & & . & . & . & . & - & . & . & . & بريد قراء & \\
\hline & & • & . & . & . & - & • & . & . & حوار صحفي & \\
\hline & & . & . & . & . & . & . & - & . & صورة وتعليق & \\
\hline & & $1 \ldots$, & $r$ & . & - & - & . & $1 \ldots, \cdot$ & r & الإجمالي & \\
\hline
\end{tabular}

أهتمت الصحف عينة البحث بالتقرير بصورة أكبر وجاء في صدارة القوالب الصحفية

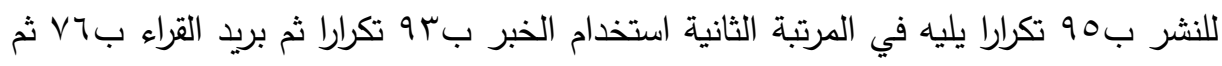
التحقيق بتكرار با مره ويشير هذا الى ضعف أهتمام الصحف للقوالب التحرير الاخرى خاصة الكاريكاتير للتوعية والرسوم البيانية والمقالات حيث لم يرد خلال فترات فترة التحليل المقال

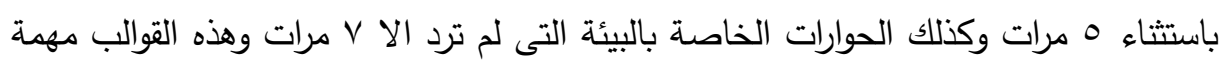

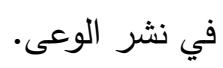


مجلة العلوم البيئية

معهد الدراسات والبحوث البيئية - جامعة عين شمس لبه

عمر احمد علي علم الدين وآخرون

جدول (؛ ):

\begin{tabular}{|c|c|c|c|c|c|c|c|c|c|c|c|}
\hline \multirow{2}{*}{ 送: } & \multirow[b]{2}{*}{$\vec{a}$} & \multicolumn{2}{|c|}{ الإجمالي } & \multicolumn{2}{|c|}{ الوفد } & \multicolumn{2}{|c|}{ المصري اليوم } & \multicolumn{2}{|c|}{ الأهرام } & \multirow{2}{*}{ تناولتها معالجة الجتى } & \multirow{2}{*}{ EE: } \\
\hline & & $\%$ & كs & $\%$ & s & $\%$ & s & $\%$ & 5 & & \\
\hline \multirow{5}{*}{$\vdots$} & \multirow{5}{*}{$\begin{array}{l}z \\
? \\
?\end{array}$} & $r \leqslant, 0$ & Y & ץ,$q$ & $v$ & 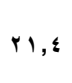 & 9 & $r q, r$ & 1. & طرح أسباب & \multirow{5}{*}{ 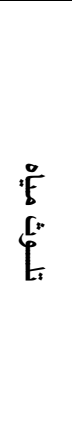 } \\
\hline & & 10,1 & 17 & $19, r$ & 0 & $18, v$ & $v$ & 1,0 & $\varepsilon$ & ورجهات النظر & \\
\hline & & $r \leqslant, q$ & rv & $r \cdot, \Lambda$ & $\wedge$ & $r \wedge, 1$ & 17 & $r \varepsilon, r$ & ir & طرح الخسائر & \\
\hline & & $r_{0,0}$ & $Y V$ & $r r, 1$ & 9 & $r r, \Lambda$ & 1. & $r \wedge, q$ & 11 & تقديم الحلول & \\
\hline & & $1 \ldots$, & 1.7 & $1 \ldots$, & Y & $r q, 7$ & $\varepsilon r$ & $r_{0, \Lambda}$ & r & الإجمالي & \\
\hline \multirow{5}{*}{$\vdots$} & \multirow{5}{*}{$\begin{array}{l}3 \\
\vdots \\
2 \\
2\end{array}$} & $r q, r$ & rr & rr,r & 9 & rA & $v$ & $r \Lambda, 1$ & 9 & طرح أسباب & \multirow{5}{*}{ 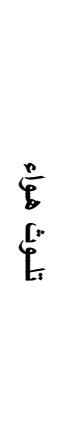 } \\
\hline & & ir & 9 & $18, v$ & $r$ & $\wedge$ & $r$ & $1 Y, 0$ & $\varepsilon$ & ورجهات النظر & \\
\hline & & $r_{0, r}$ & 19 & $r r, r$ & 1 & ry & $\wedge$ & 10,4 & ○ & طرح الخسائر & \\
\hline & & rr,r & ro & $18, v$ & $r$ & rr & $\wedge$ & $\varepsilon r, \Lambda$ & $1 \varepsilon$ & تقديم الحلول & \\
\hline & & $1 \ldots$ & $v_{0}$ & $r \varepsilon$ & 11 & $r r, r$ & ro & $\varepsilon r, V$ & rr & الإجمالي & \\
\hline \multirow{5}{*}{$\vdots$} & \multirow{5}{*}{$\begin{array}{l}5 \\
4 \\
1 \\
1 \\
1\end{array}$} & rq,. & rr & $r q, 4$ & $\wedge$ & $r q, 1$ & it & $1 \Lambda, r$ & 11 & طرح أسباب الظهور & \multirow{5}{*}{ 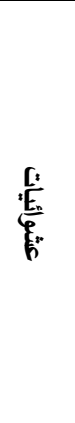 } \\
\hline & & $10, \varepsilon$ & 19 & rr,r & 9 & $\Lambda, r$ & $r$ & $11, v$ & $v$ & ورجهات النظر & \\
\hline & & $r q, r$ & rq & $r q, 7$ & $\wedge$ & rr,r & ir & $r q, v$ & 17 & طرح الخسائر & \\
\hline & & $r q, r$ & rq & $v, \varepsilon$ & r & rr, r & $\wedge$ & \& & Y & تقديم الحلول & \\
\hline & & $1 \ldots$, & Kr & YY, & $r v$ & $r q, r$ & M & $\varepsilon \wedge, \wedge$ & 7. & الإجمالي & \\
\hline
\end{tabular}


مجلة العلوم البيئية

معهد الدراسات والبحوث البيئية - جامعة عين شمس لبه

عمر احمد علي علم الدين وآخرون

\begin{tabular}{|c|c|c|c|c|c|c|c|c|c|c|c|}
\hline \multirow{2}{*}{ 点. } & \multirow{2}{*}{$\tilde{n}$} & \multicolumn{2}{|c|}{ الإجمالي } & \multicolumn{2}{|c|}{ الوفد } & \multicolumn{2}{|c|}{ المصري اليوم } & \multicolumn{2}{|c|}{ الأهرام } & \multirow{2}{*}{ تناولتها معالجة الته } & \multirow{2}{*}{$\underline{E}$} \\
\hline & & $\%$ & ك & $\%$ & ك & $\%$ & s & $\%$ & ك & & \\
\hline \multirow{5}{*}{$\vdots$} & \multirow{5}{*}{$\begin{array}{l}0 \\
0 \\
1 \\
1 \\
1\end{array}$} & $r \leq, \varepsilon$ & 19 & $r \downarrow, r$ & 0 & $r_{0,0}$ & 11 & $1 \cdot, v$ & $r$ & طرح أسباب & \\
\hline & & 11,0 & 9 & 10,1 & $r$ & $19, \varepsilon$ & 7 & $\cdot, \cdot$ & · & ووجهات النظر & \\
\hline & & $\leq r, r$ & rr & $\varepsilon v, \varepsilon$ & 9 & $r Y, T$ & v & $r \cdot, V$ & iv & طرح الخسائر & b. \\
\hline & & $r 1, \wedge$ & iv & 1,0 & $r$ & Yr, $T$ & v & $r \wedge, \uparrow$ & $\wedge$ & تقديم الحلول & \\
\hline & & $1 \ldots$, & VA & $r \leq, \varepsilon$ & 19 & $r q, v$ & rI & $r 0,9$ & YA & الإجمالي & \\
\hline \multirow{5}{*}{$\vdots$} & \multirow{5}{*}{$\begin{array}{l}y \\
\vdots \\
0 \\
>\end{array}$} & $r \wedge, \varepsilon$ & VY & $r,$. & 11 & $r r, v$ & rv & $r, r$ & r & طرح أسباب & \\
\hline & & 11,9 & rr & $19,$. & 11 & 11,0 & 15 & $\Lambda, r$ & $\wedge$ & ورجهات النظر & \\
\hline & & $r q, q$ & Vr & $r r, \Lambda$ & 19 & $r v, \varepsilon$ & $r_{1}$ & $r Y, Y$ & rr & طرح الخسائر & \\
\hline & & $r Y, \Lambda$ & $\wedge \wedge$ & $I V, r$ & 1. & $r \Lambda, r$ & rr & $\varepsilon v, \varepsilon$ & 纟 & تقديم الحلول & \\
\hline & & $1 \cdots$, & r४ו & $r 1,4$ & $0 \wedge$ & $\varepsilon r, r$ & 114 & $m 4, r$ & $9 \mathrm{~V}$ & الإجمالي & \\
\hline \multirow{5}{*}{$\ddot{<}$} & \multirow{5}{*}{$\frac{\vdots}{k}$} & $r q, Y$ & $\wedge$ & r & $r$ & $r v, 0$ & $r$ & $r \cdot, \cdot$ & $r$ & طرح أسباب & \multirow{5}{*}{$\stackrel{p}{\xi}$} \\
\hline & & $\cdot, \cdot$ & . & $\cdot, \cdot$ & · & $\cdot, \cdot$ & . & $\cdot, \cdot$ & · & ورجهات النظر & \\
\hline & & $\varepsilon \cdot, v$ & 11 & 00,4 & 0 & ro & $r$ & $\varepsilon \cdot, \cdot$ & $\varepsilon$ & طرح الخسائر & \\
\hline & & $r q, 4$ & $\wedge$ & 11,1 & 1 & $r v, 0$ & $r$ & $\varepsilon \cdot, \cdot$ & $\varepsilon$ & تقديم الحلول & \\
\hline & & $1 \cdots$, & rV & $r \mu, \mu$ & 9 & $r q, 7$ & $\wedge$ & $r v,$. & 1. & الإجمالي & \\
\hline
\end{tabular}

المجلد التاسع والأربعون، العدد السابع، الجزء السادس، يوليو • r.

الترقيم الدولي 0826-0 الانون، 
مجلة العلوم البيئية

معهد الدراسات والبحوث البيئية - جامعة عين شمس لبه

عمر احمد علي علم الدين وآخرون

\begin{tabular}{|c|c|c|c|c|c|c|c|c|c|c|c|}
\hline \multirow{2}{*}{ 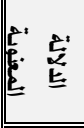 } & \multirow{2}{*}{$\bar{n}$} & \multicolumn{2}{|c|}{ الإجمالي } & \multicolumn{2}{|c|}{ الوفد } & \multicolumn{2}{|c|}{ المصري اليوم } & \multicolumn{2}{|c|}{ الأهرام } & \multirow{2}{*}{ تناولتها معالجة } & \multirow{2}{*}{$\underline{E}$} \\
\hline & & $\%$ & ك & $\%$ & ك & $\%$ & ك & $\%$ & ك & & \\
\hline \multirow{5}{*}{$\vdots$} & \multirow{5}{*}{$\begin{array}{l}< \\
a \\
a \\
<\end{array}$} & $r \cdot, r$ & $v$ & $1 \Lambda, r$ & r & 11,1 & 1 & $r \wedge, \uparrow$ & $\varepsilon$ & طرح أسباب & \multirow{5}{*}{ 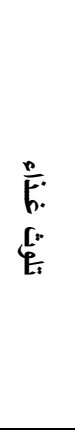 } \\
\hline & & 11,1 & $\varepsilon$ & 9,1 & 1 & 11,1 & 1 & $1 \leq, r$ & r & ورجهات النظر & \\
\hline & & $\varepsilon £, 1$ & 10 & $0 \leqslant, 0$ & 7 & 00,7 & - & $r \wedge, \uparrow$ & $\varepsilon$ & طرح الخسائر & \\
\hline & & $r r, 0$ & $\wedge$ & $1 \Lambda, r$ & r & $Y Y, Y$ & $r$ & $r \wedge, \uparrow$ & $\varepsilon$ & تقديم الحلول & \\
\hline & & $1 \ldots, \cdot$ & $r \varepsilon$ & $r r, \varepsilon$ & 11 & $r \uparrow, 0$ & 9 & $\leqslant 1, r$ & $1 \varepsilon$ & الإجمالي & \\
\hline \multirow{5}{*}{$\vdots$} & \multirow{5}{*}{$\because$} & $1 \cdot, \cdot$ & 1 & $\cdot, \cdot$ & · & $\cdot, \cdot$ & · & $r \cdot, \cdot$ & 1 & طرح أسباب & \multirow{5}{*}{ 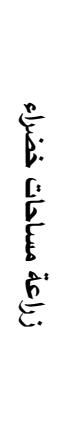 } \\
\hline & & $\cdot, \cdot$ & . & $\cdot, \cdot$ & . & $\cdot, \cdot$ & . & $\cdot, \cdot$ & . & ورجهات النظر & \\
\hline & & $\cdot, \cdot$ & · & $\cdot, \cdot$ & · & $\cdot, \cdot$ & $\cdot$ & $\cdot, \cdot$ & . & طرح الخسائر & \\
\hline & & $q_{\cdot,, \cdot}$ & 9 & $1 \ldots$, & $r$ & $1 \cdots$ & $r$ & $\wedge \cdot, \cdot$ & $\varepsilon$ & تقديم الحلول & \\
\hline & & $1 \ldots$, & 1. & $\mathrm{~V}, \varepsilon$ & $r$ & 11,1 & $r$ & 11,0 & 0 & الإجمالي & \\
\hline \multirow{5}{*}{$\because$} & \multirow{5}{*}{ 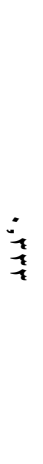 } & $0 ., \cdot$ & 1 & $\cdot, \cdot$ & · & $\cdot, \cdot$ & • & $0 ., \cdot$ & 1 & طرح أسباب & \multirow{5}{*}{ 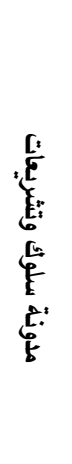 } \\
\hline & & $\cdot, \cdot$ & · & $\cdot, \cdot$ & • & $\cdot, \cdot$ & · & $\cdot, \cdot$ & · & ووجهات النظر & \\
\hline & & $\cdot, \cdot$ & · & $\cdot, \cdot$ & · & $\cdot, \cdot$ & $\cdot$ & $\cdot, \cdot$ & · & طرح الخستبة على & \\
\hline & & $0 ., \cdot$ & 1 & $\cdot, \cdot$ & · & $\cdot, \cdot$ & . & $0 ., \cdot$ & 1 & تقديم الحلول & \\
\hline & & $1, \ldots$, & r & $\cdot, \cdot$ & . & $\cdot, \cdot$ & · & $1 \cdots, \cdot$ & r & الإجمالي & \\
\hline
\end{tabular}


مجلة العلوم البيئية

معهد الدراسات والبحوث البيئية - جامعة عين شمس لبه

عمر احمد علي علم الدين وآخرون

أهتمت معظم الصحف عينة البحث بالدرجة الاولى ما بين نشر القضايا والمشكلات البيئية والتوعية ووضع حلول للمشكلة كهف صحفي للنشر في حين جاء الاهتمام بوجهة نظر الصحيفة كهدف صحفي من النشر في المرتبة الاخيرة.

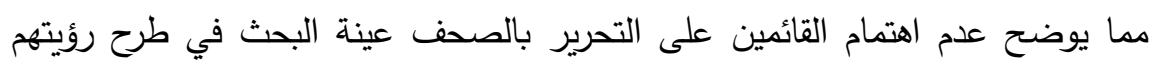
تجاه القضايا والمشكلات البيئية مثل باقى الموضوعات المقدمة على صفين صفحاتها واذا تتوع تركيز الصحف على تلك الابعاد فمن المكن أن تصبح ذات جدوى للقراء تسهم في تثقيفه وتوعيتهم

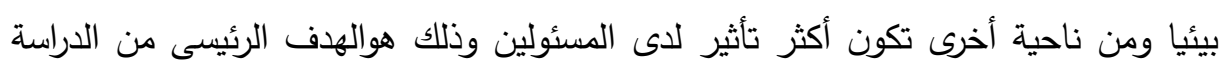
الحالية.

أوضحت النتائج الصحف عينة الدراسة أنها أهتمت بطرح الخسائر المترتبة على القضايا والمشكلات البيئية بنسبة تكرار وصلت الى بr T مرة وايضا أهتمت الصحف بالحلول والعلاج

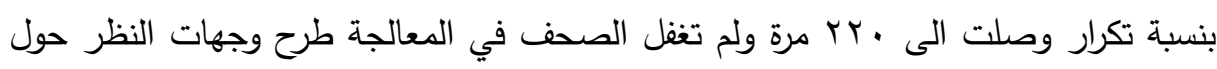

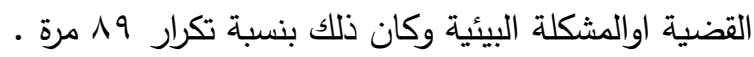

جدول(0) :

\begin{tabular}{|c|c|c|c|c|c|c|c|c|c|c|c|}
\hline \multirow{2}{*}{ 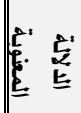 } & \multirow{2}{*}{ كا' } & \multicolumn{2}{|c|}{ الإجمالي } & \multicolumn{2}{|c|}{ الوفد } & \multicolumn{2}{|c|}{ المصري اليوم } & \multicolumn{2}{|c|}{ الأهرام } & \multirow{2}{*}{ مصدر الموضوع } & \multirow{2}{*}{ 些 } \\
\hline & & $\%$ & s & $\%$ & ك & $\%$ & ك & $\%$ & ك & & \\
\hline \multirow{8}{*}{$\vdots$} & \multirow{8}{*}{$r \leq, \leq}$. & $r \varepsilon,$. & iv & ro,. & $\varepsilon$ & $0 ., \cdot$ & 9 & ro,. & $\varepsilon$ & مسئولون & \multirow{8}{*}{$\begin{array}{l}\dot{E}^{\circ} \\
\dot{E}_{i}^{* *}\end{array}$} \\
\hline & & $\varepsilon \wedge,$. & $r \varepsilon$ & 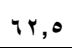 & 1. & $r, r$ & $\varepsilon$ & ir,o & 1. & صحفي & \\
\hline & & $\cdot, \cdot$ & . & $\cdot, \cdot$ & . &.,. & . & $\cdot, \cdot$ & . & وكالات أنباء & \\
\hline & & $18,$. & $\wedge$ & $1 Y, 0$ & $r$ & $r V, \Lambda$ & 0 & $7, r$ & 1 & قارئ & \\
\hline & & $\cdot, \cdot$ & . & $\cdot, \cdot$ & . & $\cdot, \cdot$ & . & $\cdot, \cdot$ & . & بحوث ودراسات & \\
\hline & & $\cdot, \cdot$ & . & $\cdot, \cdot$ & . & $\cdot$, & . & $\cdot, \cdot$ & . & ندوات ومؤتمرات & \\
\hline & & $r, \cdot$ & 1 & $\cdot, \cdot$ & . & $\cdot, \cdot$ & . & $7, r$ & 1 & خبراء & \\
\hline & & $1 \ldots$, & o. & $r r, \cdot$ & 17 & $r 4, \cdot$ & 11 & rr,. & 17 & الإجمالي & \\
\hline
\end{tabular}

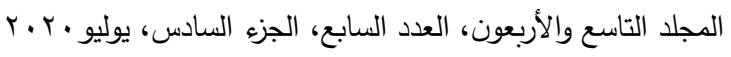

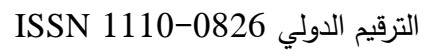


مجلة العلوم البيئية

معهد الدراسات والبحوث البيئية - جامعة عين شمس لبه

عمر احمد علي علم الدين وآخرون

\begin{tabular}{|c|c|c|c|c|c|c|c|c|c|c|c|}
\hline \multirow{2}{*}{$\underline{E}$} & \multirow{2}{*}{ كا' } & \multicolumn{2}{|c|}{ الإجمالي } & \multicolumn{2}{|c|}{ الوفد } & \multicolumn{2}{|c|}{ المصري اليوم } & \multicolumn{2}{|c|}{ الأهرام } & \multirow{2}{*}{ مصدر الموضوع } & \multirow{2}{*}{ 嗜 } \\
\hline & & $\%$ & s & $\%$ & ك & $\%$ & ك & $\%$ & s & & \\
\hline \multirow{8}{*}{$\vdots$} & \multirow{8}{*}{$r \checkmark, \leqslant \wedge \wedge$} & $r v, \Lambda$ & iv & $\leqslant 1, v$ & • & $r \cdot, \wedge$ & $\varepsilon$ & $\varepsilon$ & $\wedge$ & مسئولون & \multirow{8}{*}{$\begin{array}{l}\xi_{b}^{p} \\
\xi_{b}^{b}\end{array}$} \\
\hline & & $\leq 4, \vee$ & rl & $0 ., \cdot$ & 7 & $r \cdot, \Lambda$ & $\varepsilon$ & 00 & 11 & صحفي & \\
\hline & & \&, & r & $\cdot, \cdot$ & $\cdot$ & $10, \varepsilon$ & r & $\cdot, \cdot$ & · & وكالات أنباء & \\
\hline & & $\wedge, q$ & $\varepsilon$ & $\Lambda, r$ & 1 & $r r, 1$ & $r$ & $\cdot, \cdot$ & · & قارئ & \\
\hline & & $r, r$ & 1 & $\cdot, \cdot$ & · & $\cdot, \cdot$ & . & ○ & 1 & بحوث ودراسات & \\
\hline & & $\cdot, \cdot$ & . & $\cdot, \cdot$ & . & $\cdot, \cdot$ & . & $\cdot, \cdot$ & . & ندوات ومؤتمرات & \\
\hline & & $\cdot, \cdot$ & . & $\cdot, \cdot$ & . & $\cdot, \cdot$ & . & $\cdot, \cdot$ & . & خبراء ل & \\
\hline & & $1, \cdot, \cdot$ & $\leq 0$ & $r q, V$ & ir & $r \wedge, q$ & r & $\varepsilon \varepsilon, \varepsilon$ & $r \cdot$ & الإجمالي & \\
\hline \multirow{8}{*}{$\vdots$} & \multirow{8}{*}{ rY,rTs } & 19,8 & ir & $r, r$ & • & $1 \wedge, \wedge$ & $r$ & $1 \leq, V$ & 0 & مسئولون & \multirow{8}{*}{$\frac{\mathfrak{E}^{*}}{E_{n}}$} \\
\hline & & $r \leq, \wedge$ & r & $0 ., \cdot$ & $\wedge$ & $r v, 0$ & 7 & $r q, 0$ & 9 & صحفي & \\
\hline & & $\cdot, \cdot$ & $\cdot$ & $\cdot, \cdot$ & $\cdot$ & $\cdot, \cdot$ & . & $\cdot, \cdot$ & . & وكالات أنباء & \\
\hline & & $\leq r, \varepsilon$ & rA & $\neg, r$ & 1 & $\varepsilon r, \Lambda$ & $\mathrm{v}$ & $\bullet \wedge, \wedge$ & r. & قارئ & \\
\hline & & $r, \cdot$ & r & Ir,o & r & $\cdot, \cdot$ & · & $\cdot, \cdot$ & · & بحوث ودراسات & \\
\hline & & $\cdot, \cdot$ & $\cdot$ & $\cdot, \cdot$ & $\cdot$ & $\cdot, \cdot$ & · & $\cdot, \cdot$ & · & ندوات ومؤتمرات & \\
\hline & & $\cdot, \cdot$ & $\cdot$ & $\cdot, \cdot$ & $\cdot$ & $\cdot, \cdot$ & $\cdot$ & $\cdot, \cdot$ & . & خبراء & \\
\hline & & $1 \cdots, \cdot$ & 74 & $r \leq, r$ & 17 & $r \leqslant, r$ & 17 & 01,0 & $r \varepsilon$ & الإجمالي & \\
\hline \multirow{8}{*}{$\because$} & \multirow{8}{*}{$r, .}$. & $r q, \cdot$ & 9 & $r, r$ & $r$ & $1 \Lambda, r$ & $r$ & $\leq 0,0$ & 。 & مسئولون & \multirow{8}{*}{$\begin{array}{l}q \\
b \\
b \\
b\end{array}$} \\
\hline & & $r_{0, \Lambda}$ & $\wedge$ & r r & $r$ & 9,1 & 1 & ru, & $\varepsilon$ & صحفي & \\
\hline & & $\cdot, \cdot$ & $\cdot$ & $\cdot, \cdot$ & $\cdot$ & $\cdot, \cdot$ & . & $\cdot, \cdot$ & $\cdot$ & وكالات أنباء & \\
\hline & & $\varepsilon 0, r$ & $1 \varepsilon$ & $\varepsilon \varepsilon, \varepsilon$ & $\varepsilon$ & $V Y, V$ & $\wedge$ & $1 \Lambda, r$ & $r$ & قارئ & \\
\hline & & $\cdot, \cdot$ & . & $\cdot, \cdot$ & . & $\cdot, \cdot$ & . & $\cdot, \cdot$ & . & بحوث ودراسات & \\
\hline & & $\cdot, \cdot$ & $\cdot$ & $\cdot, \cdot$ & $\cdot$ & $\cdot, \cdot$ & $\cdot$ & $\cdot, \cdot$ & . & ندوات ومؤتمرات & \\
\hline & & $\cdot, \cdot$ & . & $\cdot, \cdot$ & . & $\cdot, \cdot$ & . & $\cdot, \cdot$ & . & خبراء ل & \\
\hline & & $1, \ldots$, & r & $r q, \cdot$ & 9 & $r 0,0$ & 11 & $r_{0,0}$ & 11 & الإجمالي & \\
\hline
\end{tabular}

238

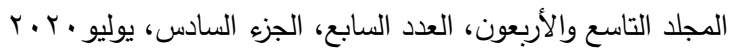

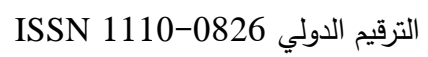


مجلة العلوم البيئية

معهد الدراسات والبحوث البيئية - جامعة عين شمس لبه

عمر احمد علي علم الدين وآخرون

\begin{tabular}{|c|c|c|c|c|c|c|c|c|c|c|c|}
\hline \multirow{2}{*}{ 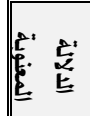 } & \multirow{2}{*}{ كاי } & \multicolumn{2}{|c|}{ الإجمالي } & \multicolumn{2}{|c|}{ الوفد } & \multicolumn{2}{|c|}{ المصري اليوم } & \multicolumn{2}{|c|}{ الأهرام } & \multirow[b]{2}{*}{ مصدر الموضوع } & \multirow{2}{*}{ 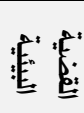 } \\
\hline & & $\%$ & ك & $\%$ & st & $\%$ & s & $\%$ & s & & \\
\hline \multirow{8}{*}{$\vdots$} & \multirow{8}{*}{$\diamond \vee, \wedge \diamond q$} & $r \varepsilon, \varepsilon$ & $\varepsilon \varepsilon$ & $\leq,, q$ & 9 & $r \wedge, r$ & iv & $r q, 1$ & 11 & مسئولون & \multirow{8}{*}{$\hat{\xi}^{*}$} \\
\hline & & $r \wedge, 1$ & ri & $\varepsilon, q$ & 9 & $1 r, r$ & $\wedge$ & $\leq 1, r$ & 19 & صحفي & \\
\hline & & $\cdot, \cdot$ & . & $\cdot, \cdot$ & . & $\cdot, \cdot$ & . & $\cdot, \cdot$ & . & وكالات أنباء & \\
\hline & & $r q, v$ & rs & $1 r, 4$ & $r$ & $01, \mathrm{~V}$ & r & $\Lambda, \vee$ & $\varepsilon$ & قارئ & \\
\hline & & $\cdot, \wedge$ & 1 & $\cdot, \cdot$ & . & $1, v$ & 1 & $\cdot, \cdot$ & . & بحوث ودراسات & \\
\hline & & $\cdot, \cdot$ & . &.,$\cdot$ & . &., & . & $\cdot, \cdot$ & . & ندوات ومؤتمرات & \\
\hline & & $\mathrm{v},$. & 9 & $\varepsilon, 0$ & 1 & $0,$. & $r$ & 1,9 & . & خبراء & \\
\hline & & $1 \cdots$, & $\begin{array}{l}\mu \\
\Lambda\end{array}$ & $i v, r$ & rr & $\leq 4,9$ & 7. & $r 0, q$ & $\leq 7$ & الإجمالي & \\
\hline \multirow{8}{*}{ 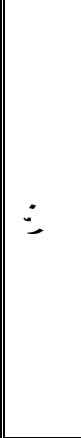 } & \multirow{8}{*}{$r, \wedge \leq ५$} & $\cdot, \cdot$ & . & $\cdot, \cdot$ & . & $\cdot, \cdot$ & . & $\cdot, \cdot$ & . & مسئولون & \multirow{8}{*}{$\stackrel{p}{\xi}$} \\
\hline & & $\varepsilon \cdot, \cdot$ & 1 & ro & 1 & ro & 1 & ov, I & $\varepsilon$ & صحفي & \\
\hline & & $\cdot, \cdot$ & . & . & . & · & . & $\cdot, \cdot$ & . & وكالات أنباء & \\
\hline & & $\varepsilon \cdot, \cdot$ & 1 & o. & $r$ & vo & $r$ & $1 \leqslant, r$ & 1 & قارئ & \\
\hline & & $\neg, \vee$ & 1 & ro & 1 & . & . & $\cdot, \cdot$ & . & بحوث ودراسات & \\
\hline & & $\cdot, \cdot$ & . & $\cdot, \cdot$ & . & $\cdot, \cdot$ & . & $\cdot, \cdot$ & . & ندوات ومؤتمرات & \\
\hline & & Ir,r & $r$ & $\cdot, \cdot$ & · & $\cdot, \cdot$ & . & o. & $r$ & خبراء & \\
\hline & & $1 \cdots$, & 10 & $r ४, V$ & $\varepsilon$ & ץ ४, V & $\varepsilon$ & $\leq 4, \vee$ & $v$ & الإجمالي & \\
\hline \multirow{8}{*}{$\because$} & \multirow{8}{*}{$\curlyvee, \varepsilon$. } & $r_{0, v}$ & 0 & ro,. & 1 & $1 \ldots$, & $\varepsilon$ & . & . & مسئولون & \multirow{8}{*}{$\begin{array}{l}\frac{b}{b} . \\
\frac{[n}{b}\end{array}$} \\
\hline & & $T \leqslant, r$ & 9 & $0 .,$. & $r$ & $0 .,$. & $r$ & $\Lambda r, r$ & 0 & صحفي & \\
\hline & & . & . & . & . & . & . & . & . & وكالات أنباء & \\
\hline & & $v, 1$ & 1 & ro,. & 1 & · & . & . & . & قارئ & \\
\hline & & . & . & . & . & . & . & . & . & بحوث ودراسات & \\
\hline & & . & . & . & . & . & . & . & . & ندوات ومؤتمرات & \\
\hline & & $v, 1$ & 1 & · & $\cdot$ & $\cdot$ & · & 19,8 & 1 & خبراء & \\
\hline & & $1 \ldots$, & $1 \leqslant$ & $r_{0,}$ & $\varepsilon$ & $r_{0, .}$ & $\varepsilon$ & $r v, 0$ & 1 & الإجمالي & \\
\hline
\end{tabular}

المجلد التاسع والأربعون، العدد السابع، الجزء السادس، يوليو • r.

الترقيم الدولي 0826-0 الانون، 
مجلة العلوم البيئية

معهد الدراسات والبحوث البيئية - جامعة عين شمس لبئه

عمر احمد علي علم الدين وآخرون

\begin{tabular}{|c|c|c|c|c|c|c|c|c|c|c|c|}
\hline \multirow{2}{*}{$\mid \begin{array}{ll}E_{0}^{2} \\
\underline{E}\end{array}$} & \multirow{2}{*}{ sir } & \multicolumn{2}{|c|}{ الإجمالي } & \multicolumn{2}{|c|}{ الوفد } & \multicolumn{2}{|c|}{ المصري اليوم } & \multicolumn{2}{|c|}{ الأهرام } & \multirow[b]{2}{*}{ مصدر الموضوع } & \multirow{2}{*}{ 唪 } \\
\hline & & $\%$ & s & $\%$ & s & $\%$ & s & $\%$ & s & & \\
\hline \multirow{8}{*}{$\vdots$} & \multirow{8}{*}{$\varepsilon, 0}$. & $1,, \cdot$ & 1 & . & . & . & . & $r_{\cdot}, \cdot$ & 1 & مسئولون & \multirow{8}{*}{ 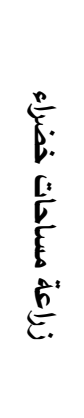 } \\
\hline & & $v \cdot, \cdot$ & $v$ & $0 .,$. & 1 & $1 \ldots$, & $r$ & $\because,$. & $r$ & صحفي & \\
\hline & & . & . & . & . & . & . & . & . & وكالات أنباء & \\
\hline & & . & . & . & . & . & . & . & . & قارئ & \\
\hline & & . & . & . & . & . & . & . & . & بحوث ودراسات & \\
\hline & & . & . & . & . & . & . & . & . & ندوات ومؤتمرات & \\
\hline & & $r \cdot, \cdot$ & $r$ & $0 .,$. & 1 & & . & $r \cdot, \cdot$ & 1 & خبراء & \\
\hline & & $1 \ldots$, & 1. & $r_{\cdot}, \cdot$ & r & $r \cdot, \cdot$ & $r$ & $0 ., \cdot$ & 0 & الإجمالي & \\
\hline \multirow{8}{*}{ a } & \multirow{8}{*}{ מrr, } & . & . & $\cdot$ & . & $\cdot$ & . & . & . & مسئولون & \multirow{8}{*}{ 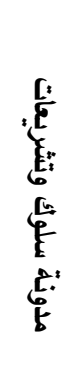 } \\
\hline & & . & . & . & . & . & . & . & . & صحفي & \\
\hline & & . & . & . & . & . & . & . & . & وكالات أنباء & \\
\hline & & . & . & . & . & . & . & . & . & قارئ & \\
\hline & & $0 .,$. & 1 & . & . & $\cdot$ & . & $0 .,$. & 1 & بحوث ودراسات & \\
\hline & & $\cdot$ & · & . & . & · & . & . & $\cdot$ & ندوات ومؤتمرات & \\
\hline & & $0 ., \cdot$ & 1 & . & . & . & . & $0 ., \cdot$ & 1 & خبراء & \\
\hline & & $1 \ldots, \cdot$ & r & $\cdot$ & $\cdot$ & $\cdot$ & $\cdot$ & $1 \cdots$, & $r$ & الإجمالي & \\
\hline
\end{tabular}

اعتمدت الصحف موضوع الدراسة على مصادر معلومات متعددة فى نشرها القضايا البيئية ما بين المسئولين والقراء والمقالات ورغم هذا لوحظ تراجع اعتماد الصحف على الفئات الاخرى وخاصة المتخصصين مما قد يضعف من مادتها الصحفية المقدمة ويقلل من الثقة فيما تقدمه نتيجة تجاهلها هذه الفئة المهمة والتى يجب على الصحف الاعتماد عليها. 
مجلة العلوم البيئية

معهد الدراسات والبحوث البيئية - جامعة عين شمس لهم آله

عمر احمد علي علم الدين وآخرون

ثانياً: تحليل الثكل:

جدول (7) :

\begin{tabular}{|c|c|c|c|c|c|c|c|c|c|c|c|}
\hline \multirow{2}{*}{ المنولالة } & \multirow{2}{*}{ كا' } & \multicolumn{2}{|c|}{ الإجمالي } & \multicolumn{2}{|c|}{ الوفـ } & \multicolumn{2}{|c|}{ المصري اليوم } & \multicolumn{2}{|c|}{ الأهرام } & \multirow[b]{2}{*}{ شكل الصورة } & \multirow{2}{*}{$E^{\prime \prime}$} \\
\hline & & $\%$ & ك & $\%$ & s & $\%$ & 5 & $\%$ & ك & & \\
\hline \multirow{5}{*}{$\cdot, 7$} & \multirow{5}{*}{$\cdot, \wedge \curlyvee \varepsilon$} & 10,9 & v & $\Lambda, r$ & 1 & rr,o & $\varepsilon$ & Ir, r & $r$ & شخصية & \multirow{5}{*}{ 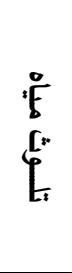 } \\
\hline & & $r \Lambda, r$ & r. & הr,r & 1. & $\leq V, 1$ & $\wedge$ & $\wedge \cdot, \cdot$ & ir & موضوعية & \\
\hline & & $\cdot, \cdot$ & . & $\cdot, \cdot$ & . & $\cdot, \cdot$ & . & $\cdot, \cdot$ & . & كاربكاتير & \\
\hline & & 10,9 & v & $\Lambda, r$ & 1 & $r q, \xi$ & • & $\mathrm{Y}, \mathrm{V}$ & 1 & بدون صورة & \\
\hline & & $1 \ldots$, & ๕ & $r v, r$ & ir & $r \wedge, \uparrow$ & iv & $r \leq, 1$ & 10 & الإجمالي & \\
\hline \multirow{5}{*}{$\cdot, r$} & \multirow{5}{*}{ r,orr } & $\mid v, \Lambda$ & $\wedge$ & $14, v$ & $r$ & $\mu_{\Lambda, 0}$ & 。 & $0,$. & 1 & شخصية & \multirow{5}{*}{$\begin{array}{l}\frac{p}{b} \\
\xi_{z}^{[*}\end{array}$} \\
\hline & & r r r & $r \varepsilon$ & r r r & $\varepsilon$ & $\varepsilon Y, r$ & 1 & v. & $1 \varepsilon$ & موضوعية & \\
\hline & & $\cdot, \cdot$ & . & $\cdot, \cdot$ & . & $\cdot, \cdot$ & . & . & . & كاريكاتير & \\
\hline & & $r \wedge, q$ & ir & $0 .,$. & 1 & $10, \varepsilon$ & $r$ & ro & - & بدون صورة & \\
\hline & & $1 \ldots$, & $\leq 0$ & $r ч, V$ & ir & $r \wedge, q$ & ir & « & $r$. & الإجمالي & \\
\hline \multirow{5}{*}{$\cdot, \ldots r$} & \multirow{5}{*}{ IY,YAT } & $1 \leqslant, r$ & 9 & $r r, 1$ & $r$ & $1 r, 0$ & $r$ & 11,1 & $\varepsilon$ & شخصية & \multirow{5}{*}{ 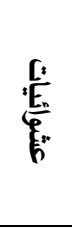 } \\
\hline & & 71,9 & rq & 11,0 & $\wedge$ & $\uparrow \wedge, \wedge$ & 11 & $\bullet \wedge, \wedge$ & $r$. & موضوعية & \\
\hline & & . & . & . & . & . & . & . & . & كاربكاتير & \\
\hline & & $r r, \Lambda$ & 10 & $10, \varepsilon$ & r & $1 \wedge, \wedge$ & $r$ & $r q, \varepsilon$ & 1. & بدون صورة & \\
\hline & & $1 \ldots$, & r & $r \cdot, r$ & 15 & $r_{0, \varepsilon}$ & 14 & $0 \varepsilon,$. & r & الإجمالي & \\
\hline \multirow{5}{*}{$\cdot, 9$} & \multirow{5}{*}{$\cdot, Y \diamond \wedge$} & $Y_{0, \Lambda}$ & $\wedge$ & £ & $\varepsilon$ & 9,1 & 1 & $r v, r$ & $r$ & شخصية & \multirow{5}{*}{$\begin{array}{l}q \\
b \\
b\end{array}$} \\
\hline & & $0 \wedge, 1$ & 11 & 00,7 & 0 & 4 & $\mathrm{v}$ & $0 \leqslant, 0$ & 1 & موضوعية & \\
\hline & & . & . & . & . & . & . & . & . & كاريكاتير & \\
\hline & & 17,1 & 。 & . & . & $r v, r$ & $r$ & $i \Lambda, r$ & $r$ & بدون صورة & \\
\hline & & $\wedge, \wedge$ & r & rq,. & 9 & ro,o & 11 & ro,0 & 11 & الإجمالي & \\
\hline \multirow{5}{*}{$\cdot, \cdot r$} & \multirow{5}{*}{$\Lambda, \cdot 7 \Lambda$} & $r \leqslant, V$ & m & r r & 11 & $r r, r$ & $1 \varepsilon$ & $r \cdot, \wedge$ & 11 & شخصية & \multirow{5}{*}{$\underline{\xi^{\prime}}$} \\
\hline & & $\varepsilon \wedge, \uparrow$ & $v_{1}$ & $0 \leqslant, 0$ & 11 & r r r & rr & $r q, 7$ & $r$ & موضوعية & \\
\hline & & $\varepsilon, \wedge$ & v & $r$ & 1 & $\Upsilon, \mathrm{V}$ & $\varepsilon$ & $r, \Lambda$ & $r$ & كاريكاتير & \\
\hline & & $r 1, q$ & rr & 9,1 & $r$ & $17, v$ & 1. & $r_{0, \Lambda}$ & 19 & بدون صورة & \\
\hline & & $1 \ldots$ & $1 \leqslant 4$ & YY,T & זr & $\varepsilon 1,1$ & 7. & $r q, r$ & or & الإجمالى & \\
\hline
\end{tabular}

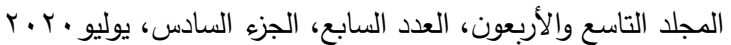

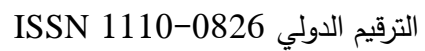


مجلة العلوم البيئية

معهد الدراسات والبحوث البيئية - جامعة عين شمس لبه

عمر احمد علي علم الدين وآخرون

\begin{tabular}{|c|c|c|c|c|c|c|c|c|c|c|c|}
\hline \multirow{2}{*}{ المعنوية } & \multirow{2}{*}{ كا' } & \multicolumn{2}{|c|}{ الإجمالي } & \multicolumn{2}{|c|}{ الوفد } & \multicolumn{2}{|c|}{ المصري اليوم } & \multicolumn{2}{|c|}{ الأهرام } & \multirow{2}{*}{ شكل الصورة } & \multirow{2}{*}{ 琒 } \\
\hline & & $\%$ & s & $\%$ & 5 & $\%$ & 5 & $\%$ & ك & & \\
\hline \multirow{5}{*}{$\cdot, 0$} & \multirow{5}{*}{$1, r}$. & . & . & . & . & . & . & . & . & شخصية & \multirow{5}{*}{$\stackrel{8}{\xi}$} \\
\hline & & 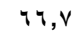 & 1. & vo & $r$ & vo & $r$ & ov, I & $\varepsilon$ & موضوعية & \\
\hline & & . & . & . & . & . & . & . & . & كاريكاتير & \\
\hline & & r,r & - & ro & 1 & ro & 1 & $\leq r, q$ & $r$ & بدون صورة & \\
\hline & & $1 \ldots$, & 10 & $r ४, V$ & $\varepsilon$ & ץ ४, & $\varepsilon$ & $\varepsilon \neg, V$ & v & الاجمالى & \\
\hline \multirow{5}{*}{$\cdot, \wedge$} & \multirow{5}{*}{., $0 \times 1$} & $r \wedge, \uparrow$ & $\varepsilon$ & o. & $r$ & o. & $r$ & . & . & شخصية & \multirow{5}{*}{ 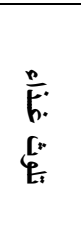 } \\
\hline & & o. & $v$ & ro & 1 & o. & r & $74, v$ & $\varepsilon$ & موضوعية & \\
\hline & & . & . & . & . & . & . & . & . & كاريكاتير & \\
\hline & & $r, \varepsilon$ & $r$ & ro & 1 & - & . & r,r & $r$ & بدون صورة & \\
\hline & & $1 \ldots$, & $1 \varepsilon$ & $r \wedge, \uparrow$ & $\varepsilon$ & $r \wedge, \uparrow$ & $\varepsilon$ & $\varepsilon r, q$ & 7 & الإجمالي & \\
\hline \multirow{5}{*}{$\cdot, 0$} & \multirow{5}{*}{$1, \varepsilon$. } & . & . & . & . & . & . & . & . & شخصية & \multirow{5}{*}{ 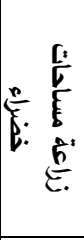 } \\
\hline & & v. & v & $1 \ldots$ & $r$ & $74, \mathrm{~V}$ & $r$ & 7. & $r$ & موضوعية & \\
\hline & & . & . & . & . & . & . & . & . & كاربكاتير & \\
\hline & & $r$. & $r$ & . & . & rr,r & 1 & $\leq$ & $r$ & بدون صورة & \\
\hline & & $1 \ldots$, & 1. & $r .,$. & $r$ & $r \cdot, \cdot$ & $r$ & $0 .,$. & 。 & الإجمالي & \\
\hline \multirow{5}{*}{$\cdot, 7$} & \multirow{5}{*}{ ת זr, } & $1 \ldots$, & r & . & . & . & . & $1 \ldots$, & $r$ & شخصية & \multirow{5}{*}{ 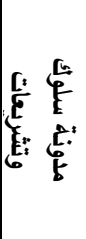 } \\
\hline & & . & . & . & . & . & . & . & . & موضوعية & \\
\hline & & . & · & . & . & . & . & . & . & كاريكاتير & \\
\hline & & . & . & . & . & . & . & . & . & باون صورة & \\
\hline & & $1 \ldots$, & $r$ & $\cdot, \cdot$ & . & $\cdot, \cdot$ & . & $1 \ldots$, & r & الإجمالي & \\
\hline
\end{tabular}

بتحليل شكل الصورة لعينة الدراسة كان الأعلى تكرارا فى صحف الدراسة للصور

(موضوعية) ثم (شخصية) ثم (بدون صورة). 
مجلة العلوم البيئية

معهد الدراسات والبحوث البيئية - جامعة عين شمس لبه

عمر احمد علي علم الدين وآخرون

جلول (V):

\begin{tabular}{|c|c|c|c|c|c|c|c|c|c|c|c|}
\hline \multirow{2}{*}{ المعنوية } & \multirow{2}{*}{ Si } & \multicolumn{2}{|c|}{ الإجمالي } & \multicolumn{2}{|c|}{ الوفـ } & \multicolumn{2}{|c|}{ المصري اليوم } & \multicolumn{2}{|c|}{ الأهرام } & \multirow{2}{*}{ الصفحة } & \multirow{2}{*}{ البيئية } \\
\hline & & $\%$ & ك & $\%$ & ك & $\%$ & كs & $\%$ & ك & & \\
\hline \multirow{4}{*}{$\cdot, \cdots 1$} & \multirow{4}{*}{$\cdot, \cdot 91$} & · & · & · & · & · & . & $\cdot$ & · & أولي & \multirow{4}{*}{ تلــوث مياه } \\
\hline & & $q \vee, v$ & $\varepsilon r$ & $1 \ldots$ & ir & $9 \leq, 1$ & 14 & $1 \ldots$ & 10 & داخلية & \\
\hline & & $r, r$ & 1 & . & . & 0,9 & 1 & . & . & أخيرة & \\
\hline & & $1 \ldots$ & $\leq \varepsilon$ & $r v, r$ & ir & $r \wedge, \gamma$ & iv & $\Gamma \leq, 1$ & 10 & الإجمالي & \\
\hline \multirow{4}{*}{$\cdot, \ldots 1$} & \multirow{4}{*}{$\varepsilon r, \cdot \wedge v$} & $\cdot, \cdot$ & · & $\cdot, \cdot$ & $\cdot$ & $\cdot, \cdot$ & $\cdot$ & $\cdot, \cdot$ & $\cdot$ & أولي & \multirow{4}{*}{ تلـوث } \\
\hline & & $1 \ldots$, & $\leq 0$ & $1 \ldots$, & ir & $1 \ldots$, & 14 & $1 \ldots$, & $r$. & داخلية & \\
\hline & & $\cdot, \cdot$ & . & $\cdot, \cdot$ & . & $\cdot, \cdot$ & . & $\cdot, \cdot$ & . & أخيرة & \\
\hline & & $1 \ldots$, & $\leq 0$ & $r q, V$ & ir & $r \wedge, q$ & ir & $\varepsilon \varepsilon, \varepsilon$ & $r$. & الإجمالي & \\
\hline \multirow{4}{*}{$\cdot, \ldots 1$} & \multirow{4}{*}{$1 . r, 1 \leqslant \mu$} & $r, r$ & r & $\cdot, \cdot$ & . & $\cdot, \cdot$ & $\cdot$ & 0,9 & $r$ & أولي & \multirow{4}{*}{ عشوائيات } \\
\hline & & $9 r, V$ & 09 & $1 \ldots, \cdot$ & ir & $\wedge \vee, \odot$ & $1 \leq$ & $9 \leq, 1$ & rr & داخلية & \\
\hline & & $r, r$ & $r$ & $\cdot, \cdot$ & . & Ir,O & $r$ & $\cdot, \cdot$ & . & أخيرة & \\
\hline & & $1 \ldots$, & r & $r \cdot, r$ & 15 & $r_{0, \varepsilon}$ & 14 & $0 \leqslant$, & & الإجمالي & \\
\hline \multirow{4}{*}{$\cdot, \cdots 1$} & \multirow{4}{*}{$r v, 1 r q$} & . & $\cdot$ & . & $\cdot$ & . & $\cdot$ & . & . & أولي & \multirow{4}{*}{ صحى صف } \\
\hline & & $94, \wedge$ & $r \cdot$ & $1 \ldots, \cdot$ & 9 & $9 ., 9$ & 1. & $1 \ldots$, & 11 & داخلية & \\
\hline & & $r, r$ & 1 & . & . & 9,1 & 1 & . & . & أخيرة & \\
\hline & & $1 \ldots$, & $r$ & rq, & 9 & $r_{0,0}$ & 11 & $r_{0,0}$ & 11 & الإجمالي & \\
\hline \multirow{4}{*}{$\cdot, \cdots 1$} & \multirow{4}{*}{ YY४, १人 } & $\cdot, \wedge$ & 1 & . & . & $1, v$ & 1 & . & . & أولي & \multirow{4}{*}{ القمامة } \\
\hline & & 94,1 & IRT & $9 ., 9$ & $r$. & $90,$. & ov & $1 \ldots$, & $\leq 4$ & داخلية & \\
\hline & & $r, 1$ & $\varepsilon$ & 9,1 & $r$ & $r, r$ & $r$ & . & . & أخيرة & \\
\hline & & $1 \ldots$, & IYA & $r \wedge, r$ & rr & $\leq 4,9$ & 7. & $r_{1,0}$ & \ & الإجمالي & \\
\hline \multirow{4}{*}{$\cdot, \cdots$} & \multirow{4}{*}{$\wedge, \cdot$ T } & . & . & . & · & . & . & . & . & أولي & \multirow{4}{*}{ ضوضـاء } \\
\hline & & $\wedge \uparrow, \vee$ & ir & $1 \ldots$, & $\varepsilon$ & $v_{0,}$. & $r$ & $\wedge_{0, v}$ & 1 & داخلية & \\
\hline & & r & r & . & . & $r_{0, .}$ & 1 & $1 \leqslant, r$ & 1 & أخيرة & \\
\hline & & $1 \ldots$, & 10 & $r q, V$ & $\varepsilon$ & $r q, V$ & $\varepsilon$ & $\leqslant \curlyvee, V$ & v & الإجمالي & \\
\hline
\end{tabular}

المجلد التاسع والأربعون، العدد السابع، الجزء السادس، يوليو •r.r.

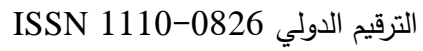


مجلة العلوم البيئية

معهد الدراسات والبحوث البيئية - جامعة عين شمس لبه

عمر احمد علي علم الدين وآخرون

\begin{tabular}{|c|c|c|c|c|c|c|c|c|c|c|c|}
\hline \multirow{2}{*}{ الدعلالة } & \multirow{2}{*}{ كان } & \multicolumn{2}{|c|}{ الإجمالي } & \multicolumn{2}{|c|}{ الوفد } & \multicolumn{2}{|c|}{ المصري اليوم } & \multicolumn{2}{|c|}{ الأهرام } & \multirow{2}{*}{ الصفحة } & \multirow{2}{*}{ البيئية } \\
\hline & & $\%$ & ك & $\%$ & s & $\%$ & ك & $\%$ & كs & & \\
\hline \multirow{4}{*}{$\cdot, \ldots$} & \multirow{4}{*}{$1 \cdot, r \wedge 4$} & $v, 1$ & 1 & . & . & . & . & $14, v$ & 1 & أولي & \multirow{4}{*}{ تلوث غـذاء } \\
\hline & & 94,9 & ir & $1 \ldots$, & $\varepsilon$ & $1 \ldots$, & $\varepsilon$ & Ar,r & - & داخلية & \\
\hline & & . & . & . & . & . & . & . & . & أخيرة & \\
\hline & & $1 \ldots, \cdot$ & $1 \varepsilon$ & $\curlyvee \wedge, \uparrow$ & $\varepsilon$ & $r \wedge, \uparrow$ & $\varepsilon$ & $\varepsilon r, q$ & 9 & الإجمالي & \\
\hline \multirow{4}{*}{$\cdot, \cdot 1$} & \multirow{4}{*}{$7, \xi}$. & . & . & . & . & . & . & . & . & أولي & \multirow{4}{*}{ خضاحات } \\
\hline & & $9 .,$. & 9 & $1 \ldots$, & r & $74, \mathrm{~V}$ & $r$ & $1 \ldots$, & - & داخلية & \\
\hline & & $1,, 0$ & 1 & & . & $r \mu, r$ & 1 & . & . & أخيرة & \\
\hline & & $1 \ldots$, & 1. & $r \cdot, \cdot$ & $r$ & r.,. & $r$ & $0 ., \cdot$ & 0 & الإجمالي & \\
\hline \multirow{4}{*}{ •, } & \multirow{4}{*}{ תrre } & . & . & . & . & . & . & . & . & أولي & \multirow{4}{*}{ مدونة } \\
\hline & & $1 \ldots$ & $r$ & . & . & . & . & $1 \ldots$, & $r$ & داخلية & \\
\hline & & . & . & . & . & . & . & . & . & أخيرة & \\
\hline & & $1 \ldots$ & r & . & . & . & . & $1 \ldots$, & r & الإجمالى & \\
\hline
\end{tabular}

وتثير نتائج تحليل الثكل لفئة الصفحة عينة الدراسة (انه تم تتاول قضايا البيئة دائما

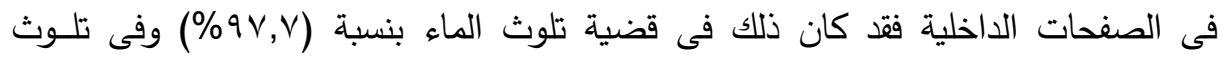

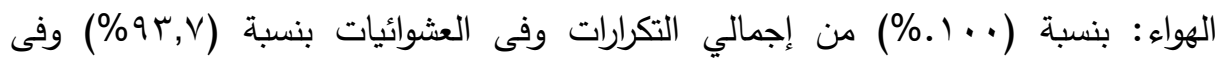

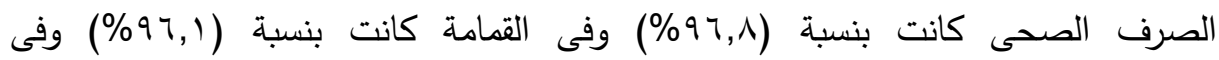

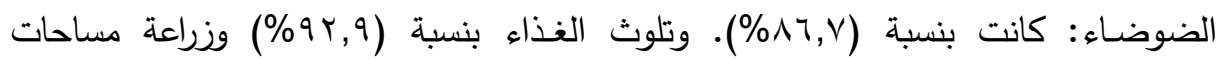

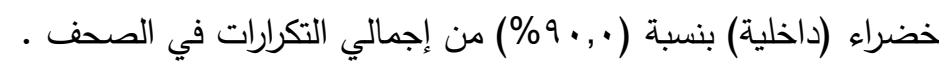

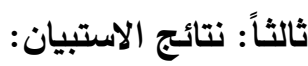

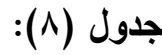

\begin{tabular}{|c|c|c|}
\hline النسبة & العدد & الإجابة \\
\hline$\% \uparrow, \vee$ & $r$ & $y$ \\
\hline \%q4,r & $r \Lambda$ & نعم \\
\hline$\% 1 \ldots$ & $r$. & الإجمالى \\
\hline
\end{tabular}


مجلة العلوم البيئية

معهد الدراسات والبحوث البيئية - جامعة عين شمس لبئة

عمر احمد علي علم الدين وآخرون

عدد رؤساء الاحياء الذين يتابعون الصحف من عينة الدراسة التى شملت .ب مبحوثا

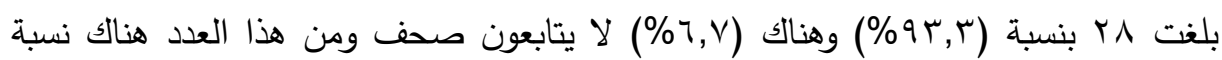

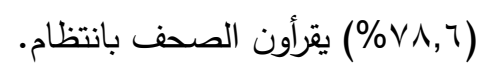

جلول (9):

\begin{tabular}{|c|c|c|c|c|c|c|}
\hline \multicolumn{2}{|c|}{$y$} & \multicolumn{2}{|c|}{ أحيانا } & \multicolumn{2}{|c|}{ دائما } & \multirow{2}{*}{ الصحيفة } \\
\hline النسبة & العدد & النسبة & العدد & النسبة & العدد & \\
\hline . & . & . & . & $1 \ldots$ & rA & الأهرام \\
\hline . & . & 0. & $1 \varepsilon$ & $Y \Lambda, \uparrow$ & $\Lambda$ & المصرى اليوم \\
\hline . & . & $r, \tau$ & 1 & r $1, \varepsilon$ & 7 & الوفد \\
\hline
\end{tabular}

احتلت الاهرام المرتبة الاولى كأفضلية لرؤساء الاحياء عينة البحث وبنسبة أقل كان

متابعة المصرى اليوم بينما جاءت متابعة جريدة الوفد في المرتبة الاخيرة بنسبة قراءة محدودة.

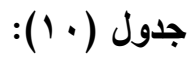

\begin{tabular}{|c|c|c|}
\hline النسبة & العدد & الموضوعات البيئية \\
\hline $1 v, 9$ & 0 & الأخبار البيئية \\
\hline$\varepsilon\rceil, \varepsilon$ & 14 & المشاكل البيئة \\
\hline$\cdot$ & $\cdot$ & الحوارات الخاصة البيئية \\
\hline$r_{0, V}$ & 1. & التحقيقات والمتابعات البيئية \\
\hline$\vee \wedge, 7$ & rt & شكاوى المواطنين البيئية \\
\hline \multirow[t]{2}{*}{$v, r$} & r & التغطيات المصورة البيئية \\
\hline & & أخرى: \\
\hline$r, \tau$ & 1 & اتابع المشكلات التى تاتى من المحافظة واسعى لحلها \\
\hline$r, \tau$ & 1 & اتابع ما يتعلق بالشان البيئي \\
\hline$r, \tau$ & 1 & اخبار المحليات \\
\hline$r, \tau$ & 1 & الاعلام \\
\hline$r, \tau$ & 1 & المحافظات \\
\hline$r, \tau$ & 1 & 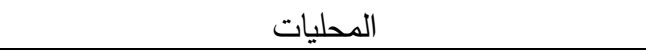 \\
\hline$r, r$ & 1 & المحليات عموما \\
\hline
\end{tabular}

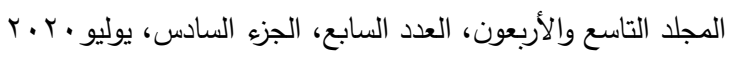

245

الترقيم الدولي 0826- ISSN 1110 
مجلة العلوم البيئية

معهد الدراسات والبحوث البيئية - جامعة عين شمس لبه

عمر احمد علي علم الدين وآخرون

\begin{tabular}{|c|c|c|}
\hline النسبة & 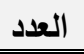 & الموضوعات البيئية \\
\hline$r, 7$ & 1 & المقالات \\
\hline$r, 7$ & 1 & الملوثات \\
\hline$r, r$ & 1 & الموضوعات العامة \\
\hline$r, \tau$ & 1 & ما يتعلق بالإدارة المحلية \\
\hline
\end{tabular}

اتضح من الاستبيان أن أهم ما يتابعه رؤساء الاحياء فى الصحف من قضايا ومشكلات

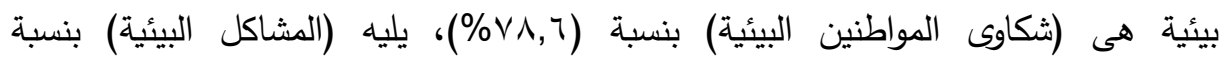

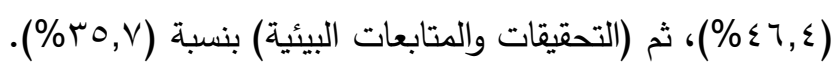

جدول (1):

\begin{tabular}{|c|c|c|}
\hline النسبة & العدد & الإجابة \\
\hline$\% \uparrow, \vee$ & $r$ & $\gamma$ \\
\hline$\% q \mu, r$ & rA & نعم \\
\hline$\% 1 \ldots$ & $r$. & الإجمالي \\
\hline
\end{tabular}

هناك مكتب أو علاقات عامة لمتابعة ما يكتب بشأن الحي بنسبة (r,rq\%) من الاحياء عينة الدراسة.

جدول (Y I):

\begin{tabular}{|c|c|c|}
\hline النسبة & العدد & الإجراء ات \\
\hline 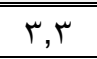 & 1 & أثث في المعلومات دون الرجوع لمصادر أخرى \\
\hline $7 \cdot, \cdot$ & 11 & أتحقق من المعلومات من مصادر أخرى \\
\hline $1 \cdot, \cdot$ & $r$ & أقارن المعلومات التى شاهدتها في الصور بقناعاتى الشخصية \\
\hline$\cdot$ & $\cdot$ & أمتتع عن متابعة الصحيفة بعد ذلك \\
\hline$\varepsilon \cdot, \cdot$ & Ir & اتخذ القرار مباشرة \\
\hline$\cdot$ & $\cdot$ & أخرى: \\
\hline$r, r$ & 1 & احاسب نفسي والمسؤلين معى \\
\hline$r, r$ & 1 & اخذ اجراء والمتابعة \\
\hline
\end{tabular}


مجلة العلوم البيئية

معهد الدراسات والبحوث البيئية - جامعة عين شمس لبئة

عمر احمد علي علم الدين وآخرون

يتم اتخاذ القرار فى المشكلات والقضايا البيئية التى يتم عرضها فى الصحف بعد التحقق

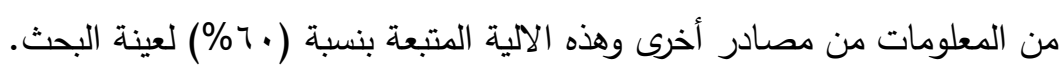
جدول (T I ):

\begin{tabular}{|c|c|c|}
\hline النسبة & العدد & الإجابة \\
\hline$\varepsilon 7, V$ & $1 \varepsilon$ & $\gamma$ \\
\hline Or, r & 17 & نعح \\
\hline$\% 1 \ldots$ & r. & الإجمالى \\
\hline
\end{tabular}

غالبية رؤساء الاحياء لا يعتبرون الصحف مصدر لمعلوماتهم عن المشاكل والقضايا

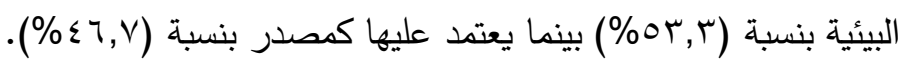

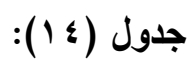

\begin{tabular}{|c|c|c|}
\hline النسبة & العدد & الوسائل \\
\hline or, r & 17 & العلاقات العامة \\
\hline $1 \cdot, \cdot$ & $r$ & البريد الالكتروني \\
\hline$r q, V$ & 11 & الاتصال بالهاتف \\
\hline $1 \cdot, \cdot$ & r & شبكات التواصل الاجتماعي (فيس بوك، تويتر ، واتس أب) \\
\hline
\end{tabular}

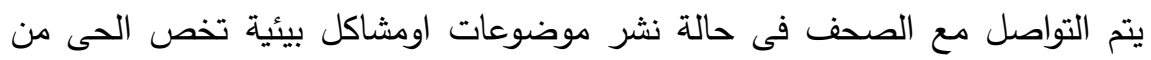

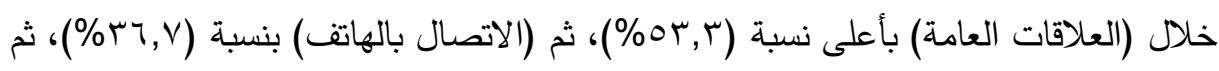

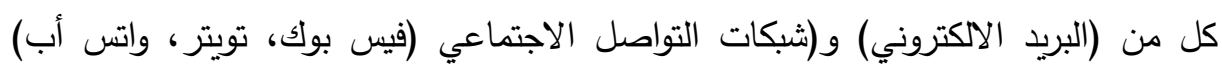

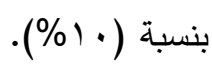


مجلة العلوم البيئية

معهد الدراسات والبحوث البيئية - جامعة عين شمس لبه

عمر احمد علي علم الدين وآخرون

جدول (0):

\begin{tabular}{|c|c|c|}
\hline النسبة & 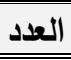 & المشكلات البيئية \\
\hline 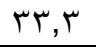 & 1. & 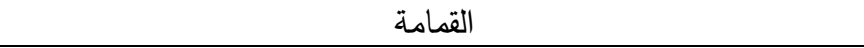 \\
\hline 17,0 & 0 & القهامة والعشوائيات \\
\hline 9,9 & r & القمامة والبناء المخالف \\
\hline 7,7 & r & القمامة وتلوث المياه \\
\hline 7,7 & r & العشوائيات \\
\hline r & 1 & العشوائية وانتشار الاشغالات والنظافة \\
\hline$r, r$ & 1 & تراكم القمامة ومخلفات المبانى والهام \\
\hline$r, r$ & 1 & القمامة وعودة الخنازير في اماكن صحراوية \\
\hline r r & 1 & المخلفات وتلوث المياه وضعفها \\
\hline$r, r$ & 1 & النظافة هي المشكلة الرئيسية ومناطق البناء العشوائى والأسواق عشوائية \\
\hline r, r & 1 & تجميعات القمامة ومشاكل الصرف الصحي \\
\hline 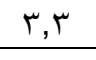 & 1 & صرف الصحي وخاصة صرف الصحي العشوائيات \\
\hline r, r & 1 & مشكلة الصرف الصحي والقهامة والقاء مخلفات البناء في الشارع \\
\hline
\end{tabular}

اظهر الاستبيان أن أهم المشكلات البيئية التى تواجه الاحياء كانت (القمامة) بنسبة

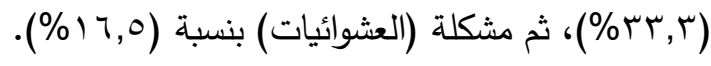

جدول (17):

\begin{tabular}{|c|c|c|}
\hline النسبة & العدد & نسبة الثكاوى التي تم حلها \\
\hline . & $\cdot$ & أقل من ·0\% \\
\hline$r, r$ & $\varepsilon$ & 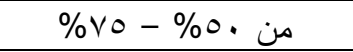 \\
\hline 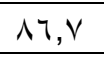 & YT & أكثر من \%vo \\
\hline$\% 1 \ldots$ & $r$. & الإجمالى \\
\hline
\end{tabular}

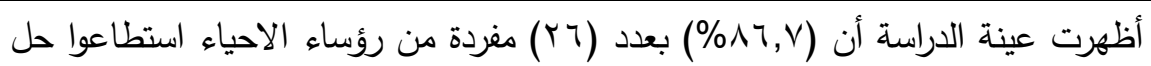

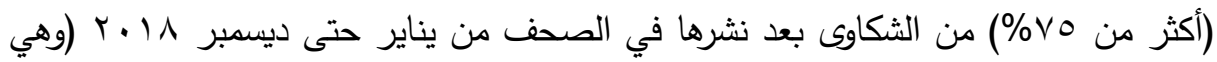

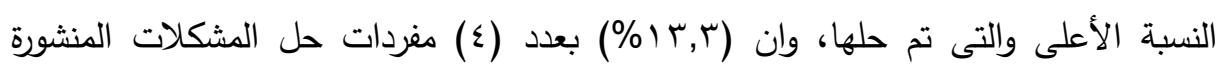

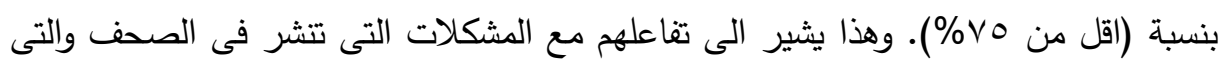

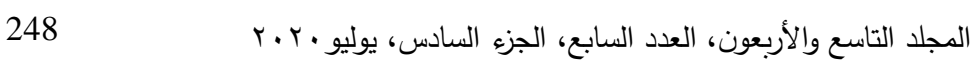

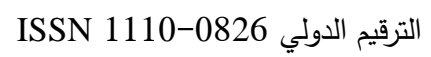


مجلة العلوم البيئية

معهد الدراسات والبحوث البيئية - جامعة عين شمس لبئة

عمر احمد علي علم الدين وآخرون

يتم تلقيها من خلال متابعتهم الثخصية أورصدها من مكاتب العلاقات العامة أوارسالها من المحافظة.

جدول (IV):

\begin{tabular}{|c|c|c|}
\hline النسبة & العدد & المشكلات البيئية \\
\hline or, r & 17 & القمامة \\
\hline$r \mu, r$ & v & العشوائيات \\
\hline$r \cdot, \cdot$ & 1 & الاشغالات \\
\hline $17, \mathrm{~V}$ & 0 & مخالفات البناء \\
\hline $1 \Gamma, r$ & $\varepsilon$ & الصرف الصحي \\
\hline $7, V$ & $r$ & رصف الطرق \\
\hline$r, r$ & 1 & المياه \\
\hline$r, r$ & 1 & الكهرباء \\
\hline$r, r$ & 1 & إطفاء أعمدة الإنارة \\
\hline
\end{tabular}

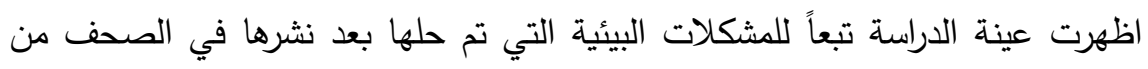

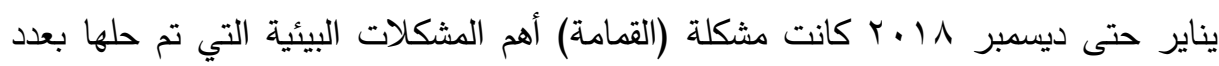

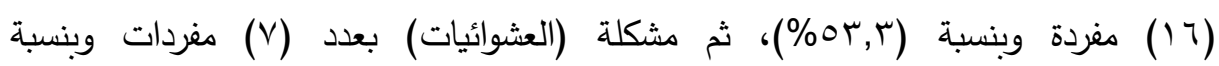

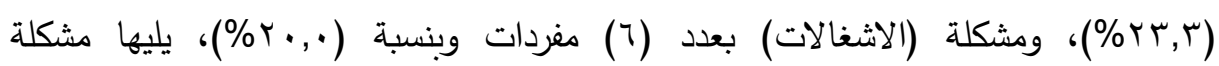

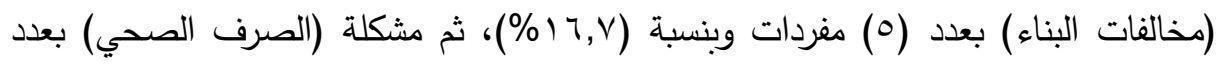

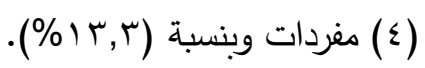

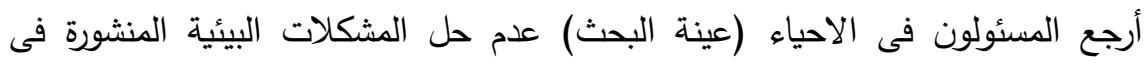
الصحف بنسبة ... 1\% لعدة أسباب أهمها: • عدم الاختصاص مثل: انتشار المواد المخدرة فى بعض الاماكن وهى من اختصاص الهاص

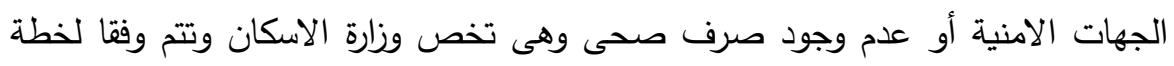
قومية او بعض المشاكل البيئية الاخرى. 


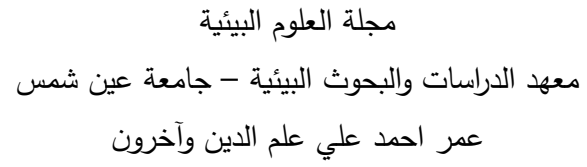

• عدم احقية الثاكى فيما يطلبه مثل طلب توصيل مرافق لمباني مخالفة.

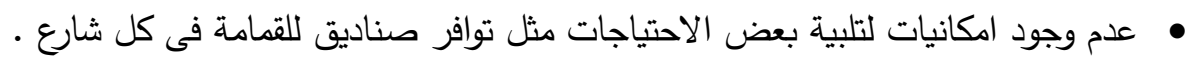

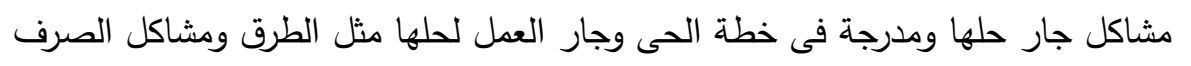
والمياه.

وهذا يؤكد ما توصلت اليه الدراسة من أن الصحف توثر على المسئولين بالأحياء

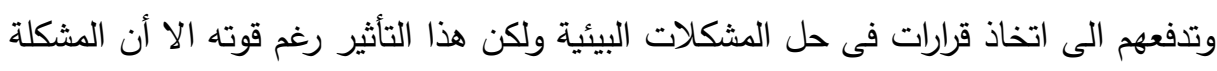
فى متابعة رؤساء الاحياء لعدد محدود جدا من الصحف او صحيفة واحدة بشكل دائم وهى آلى

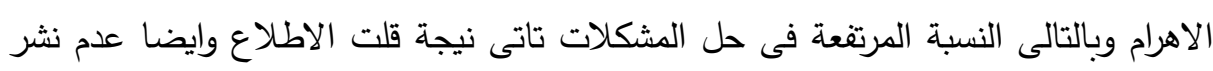
المشكلات البيئية بكثافة فى الصحف عينة الدراسة.

\section{ترويايت المهيد}

في ضوء مشكلة الدراسة وبناء على النتائج التي توصلت اليها توصى بالآتي:

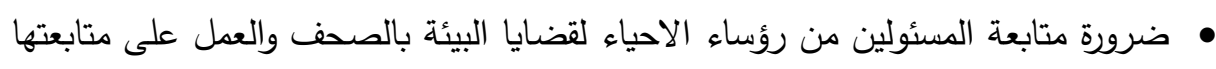
وحلها. • أهتمام الصحافة بعرض المشكلات وكتابتها بطريقة تسهم في شد انتباه المسئولين.

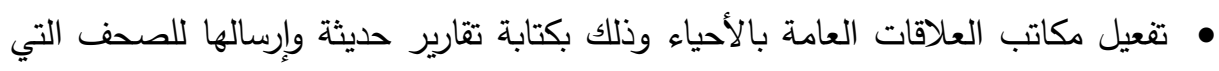
تعلقت بحل مشكلات بيئية.

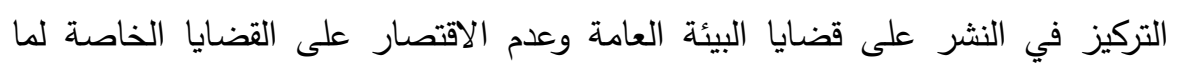
تعكسه هذه القضايا من اهتمام يتعلق بعدد كبير من جمهور القراء.

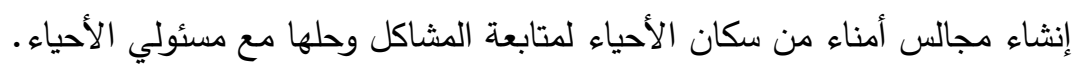


وقت اقترحت الدراسة بناء دراسات أخرى تتناول:

استخدام قادة الرأي للهواتف المحمولة في متابعة القضايا البيئية دراسة تطبيقية.

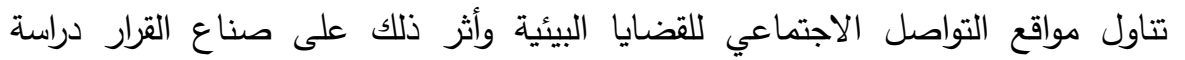

تحليلية.

\section{المراني}

أحمد زكى بدوى: معجم مصطلحات الإعلام، طץ، دار الكتاب المصرى - القاهرة - ودار الكتاب اللبنانى بيروت ع9 199 1.

أسامه غرابية؛ يحي فرحان (9^v) (1): المدخل إلى العلوم البيئة. الاردن: عمان، دار الثريعة،

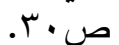

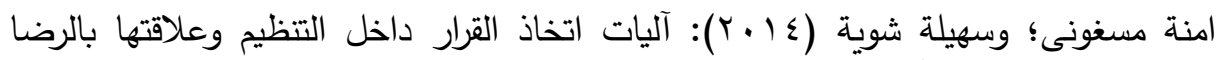
على الأداء الوظيفي. رسالة ماجستير جامعـة الثهيد حمه لخضر - الجزائر.

خليل صابات (9VVV) (1): الصحافة والتوعية بالقضايا البيئية، الاعلام العربى والقضايا البيئية، ص:11 (1)

عبد المسيح سمعان عبد المسيح (ب9919): القضايا البيئيه كما تقدمها الصحافه المصريه، رساله دكتوراه، معهد الدراسات والبحوث البيئيه جامعه عين شمس.

مجاني باديس (Y V V V): دور الإعلام في نشر الوعي البيئي، رسالة دكتوراة غير منشورة،

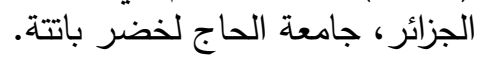

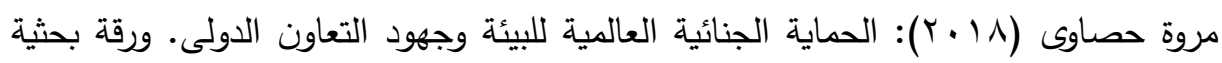

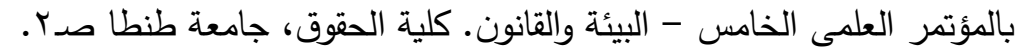

نواف كنعان (991): اتخاذ القرارات الادارية بين النظرية والتطبيق، دار الثقافة الجامعة،

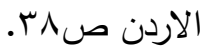

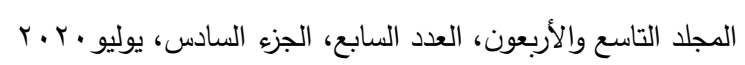

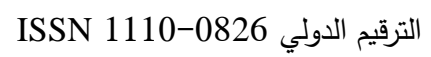




$$
\begin{aligned}
& \text { مجلة العلوم البيئية } \\
& \text { معهد الدراسات والبحوث البيئية - جامعة عين شمس لإسل } \\
& \text { عمر احمد علي علم الدين وآخرون }
\end{aligned}
$$

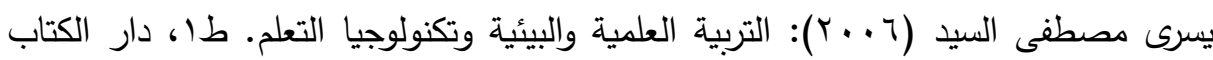
العالمى وعالم الكتب الحديثة، الاردن.

Betsy Bynum (2016): IT'S TOO DARN HOT: How Rising Temperatures are linked to Climate Change in The U.S.print Media, the degree of Master of Arts, Tufts University.

Media History Monographs 11:1.2008 - 2009. E. M. Palmegiano, St.

THE EFFECT OF WHAT NEWSPAPERS PRESENT ON ADVANCING DECISION-MAKING MECHANISMS FOR NEIGHBORHOOD OFFICIALS IN SOLVING ENVIRONMENTAL PROBLEMS

AN ANALYTICAL STUDY

\section{Omar Alam El-Din ${ }^{(1)}$; Abdel Messeh S. Abdel Messeh ${ }^{(2)}$ Marwa Yassin ${ }^{(3)}$}

1) Roza Elyousif Magazine 2) Institute of Environmental Studies and Research, Ain Shams University 3) Faculty of ..., BaniSuif University

\section{ABSTRACT}

This research drives at monitoring and analyzing the treatment of the impact of what newspapers provide for pushing decision-making mechanisms for quarters officials in solving environmental problems. The research has used the survey method and the content analysis two tools (form - content), designing also a questionnaire form for quarters' officials.

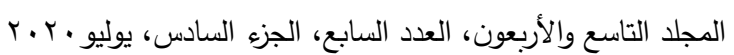

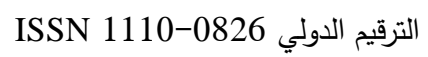




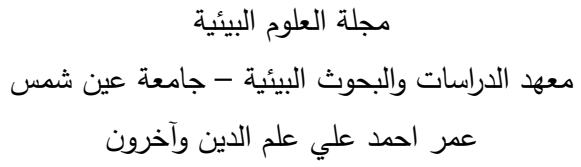

The study sample is represented in the period from January $1^{\text {st }}$, 2018 to December 31, 2018 for the newspapers of Al-Ahram, Al-Masry El-Youm and Al-Wafd.

The study reaches several results, the most important of which is that the number of environmental issues included in the study have reached (352) newspapers, distributed across (146) Al-Ahram, (128) Al-Masry Al-Youm, and (78) Al-Wafd, indicating greater interest by Al-Ahram newspaper. The issue of garbage and its problems has occupied the first rank.

The results of the questionnaire show that the quarters chiefs deal with all environmental problems published in the newspapers, and $(86.7 \%)$ of the them have resolved $(75 \%)$ of the complaints.

The study recommends finding communication channels between journalists and officials' offices to work on solving problems and establishing trusts of neighborhood residents to follow up problems and solve them with officials.

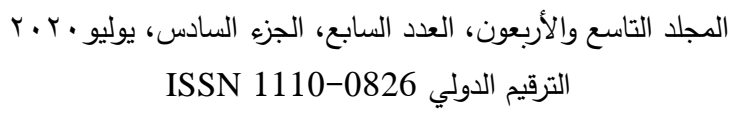

